\title{
Applications of UAV Thermal Imagery in Precision Agriculture: State of the Art and Future Research Outlook
}

\author{
Gaetano Messina ${ }^{(1)}$ and Giuseppe Modica *(-) \\ Dipartimento di Agraria, Università degli Studi Mediterranea di Reggio Calabria, Località Feo di Vito, \\ I-89122 Reggio Calabria, Italy; gaetano.messina@unirc.it \\ * Correspondence: giuseppe.modica@unirc.it; Tel.: +39-0965-1694261
}

Received: 16 March 2020; Accepted: 6 May 2020; Published: 8 May 2020

\begin{abstract}
Low-altitude remote sensing (RS) using unmanned aerial vehicles (UAVs) is a powerful tool in precision agriculture (PA). In that context, thermal RS has many potential uses. The surface temperature of plants changes rapidly under stress conditions, which makes thermal RS a useful tool for real-time detection of plant stress conditions. Current applications of UAV thermal RS include monitoring plant water stress, detecting plant diseases, assessing crop yield estimation, and plant phenotyping. However, the correct use and interpretation of thermal data are based on basic knowledge of the nature of thermal radiation. Therefore, aspects that are related to calibration and ground data collection, in which the use of reference panels is highly recommended, as well as data processing, must be carefully considered. This paper aims to review the state of the art of UAV thermal RS in agriculture, outlining an overview of the latest applications and providing a future research outlook.
\end{abstract}

Keywords: unmanned aerial vehicles (UAVs); remote sensing (RS); thermal UAV RS; thermal infrared (TIR); precision agriculture (PA); crop water stress monitoring; plant disease detection; yield estimation; vegetation status monitoring

\section{Introduction}

Remote sensing (RS) is the practice of obtaining information regarding an object, an area, or a phenomenon through the analysis of images acquired by means of a device that does not make physical contact with them [1]. RS investigations are mostly based on the development of a deterministic relationship between the amount of reflected emitted or backscattered electromagnetic energy, in specific bands or frequencies, and the chemical, biological, and physical characteristics of the studied phenomena. Conventionally, RS has been associated with satellites and manned aircrafts equipped with different sensors [2]. In recent years, considerable technological developments-mainly concerned with the use of unmanned aerial vehicle (UAV) platforms-have been registered [3]. Born for military applications, UAVs have become a common tool for use in geomatics for data acquisition in various research and operational fields: regional security, monitoring of structures and infrastructures, monitoring of archeological sites, environmental monitoring, application in agriculture, etc. $[2,4,5]$. Indeed, low-altitude RS by means of UAVs is one of the most powerful tools in precision agriculture (PA).

The International Society of Precision Agriculture (ISPAG) defines PA as "a management that gathers, processes and analyzes temporal, spatial and individual data and combines it with other information to support management decisions according to estimated variability for improved resource use efficiency, productivity, quality, profitability and sustainability of agricultural production" 
(www.ispag.org, last access 18 April 2020). The general stages of PA practice involve data collection, field variability mapping through the use and development of algorithms, decision making, and management practice [6].

In this framework, thermal RS has been found to be a promising tool by measuring surface temperature [7]. In the last years, thermal sensors have also gained popularity because of the improvements in sensor technology and the reduction in costs. The surface temperature detected by thermal sensors has been found to be a rapid response variable to monitor plant growth and stress $[7,8]$. Indeed, the temperature is a fundamental environmental variable that plays an essential role in plant physiological processes, such as transpiration, leaf water potential, and photosynthesis [9].

The potentialities of the application of thermal UAV RS concern several mapping and monitoring issues, such as yield estimation, plant phenotyping [10,11], plant water stress detection [12,13], and plant disease detection [14], as explained in the further paragraphs of this review. When considering these last two applications, the capability to identify, using sensors mounted on UAVs, crop stress, and health before said crops are significantly damaged could be a crucial goal.

Concerning water stress, it has been found that thermal images show a correlation between minor changes in water stress that are undetectable by the normalized difference vegetation index (NDVI) [15]. In this regard, temperature-based indices represent a fast and practical way to evaluate and estimate crop water status, indicating plants' water content [16]. Among these indices, the crop water stress index (CWSI) [17], which is the most used, is often exploited to monitor plants' water status and, therefore, for the management of irrigation [18]. Such indices have been applied to different crops, both tree and herbaceous, such as olives [19], grapevines [20], sugar-beet [21], maize [22], rice [23], wheat and cotton [24].

However, the correct interpretation and use of a thermal image are based on basic knowledge of the nature of thermal radiation [1]. Thermal images can be influenced by various factors, including the characteristics of the thermal camera, meteorological conditions, and several sources of emitted and reflected thermal radiation [7]. For this reason, the aspects that are related to calibration, ground data collection, the step in which the use, and the measurement of the temperature of reference panels are recommended [25], and data processing must be carefully carried out for correct temperature retrieval.

The objective of this review is to cover the state of the art of thermal UAV RS in the framework of PA, outlining an overview of the latest applications. The structure of this paper is as follows. In Section 2, a brief description of the basic principles of thermography is provided. Section 3 deals with the characteristics of thermal cameras; the calibration, data collection, and data processing aspects are discussed. Section 4 is devoted to the main thermal RS in PA. Finally, in Section 5, we provide the present-as well as future-challenges in thermal RS.

\section{Basic Principles of Thermography}

Thermal RS uses the information at the emitted radiation in the thermal infrared (TIR) range (Figure 1) of the electromagnetic (EM) spectrum [26]. This information is converted into temperature [7]. Two categories can be distinguished within the IR region $(0.7-100 \mu \mathrm{m})$, namely, the reflected-IR $(0.7-3.0 \mu \mathrm{m})$ and TIR $(3.0-100 \mu \mathrm{m})$. Generally, all of the elements of the landscape, such as vegetation, soil, water, and people, emit TIR radiation in the 3.0-14 $\mu \mathrm{m}$ portion of the EM spectrum [27].

In this range of the EM spectrum, part of the IR energy is transmitted to the Earth's surface through two so-called atmospheric windows that range from 3 to $5 \mu \mathrm{m}$ and from 8 to $14 \mu \mathrm{m}$ [28] (Figure 2). Almost all of the radiation between 5 and $8 \mu \mathrm{m}$ is absorbed by atmospheric gasses (i.e., water, carbon dioxide (CO2), and ozone (O3) molecules), as indicated in Figure 2 [27] (Figure 2). 


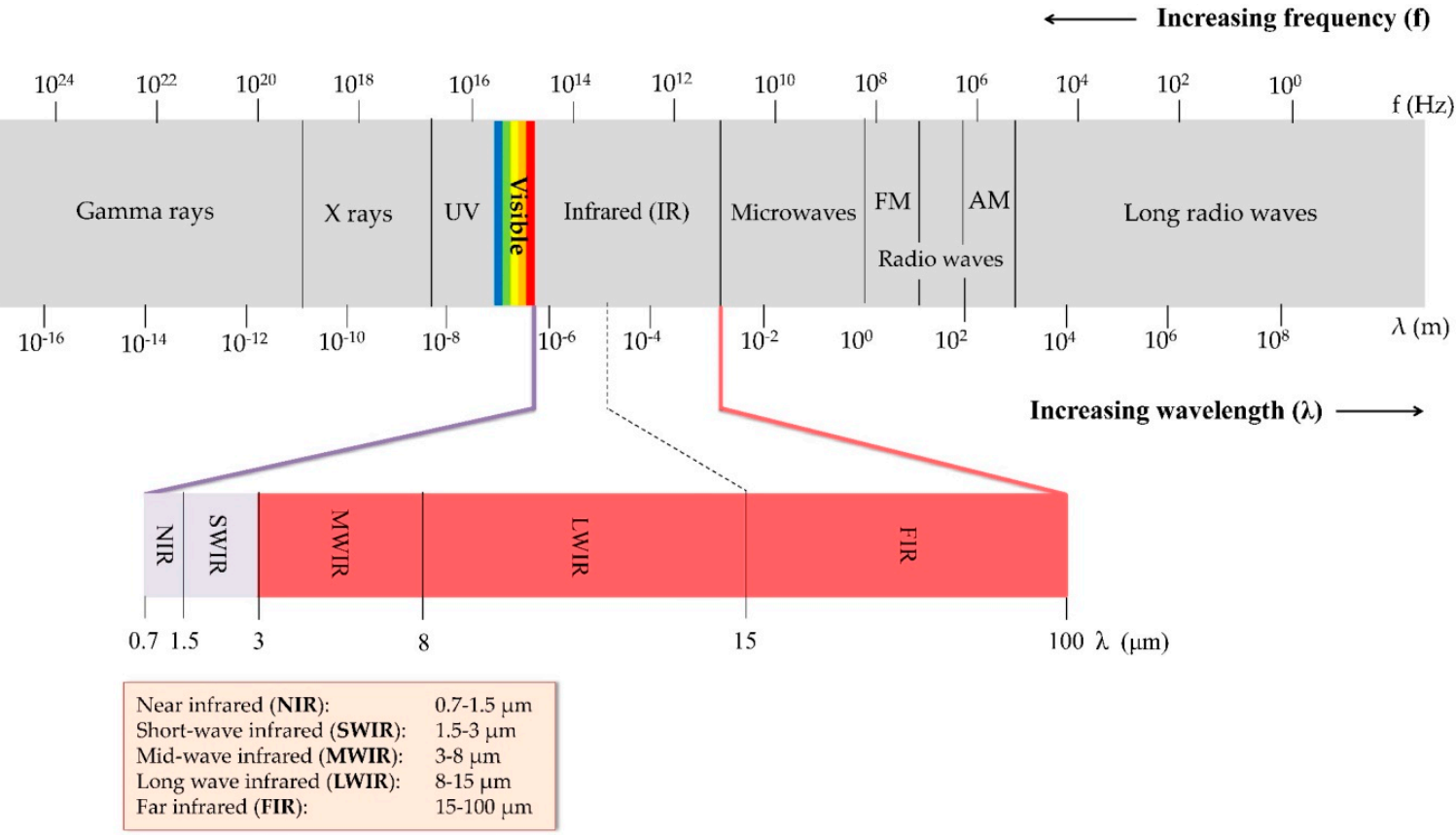

Figure 1. The electromagnetic (EM) spectrum. In evidence, the infrared (IR) region, in which the reflected-IR $(0.7-3.0 \mu \mathrm{m})$ and the emitted-IR $(3.0-100 \mu \mathrm{m})$ are further detailed.

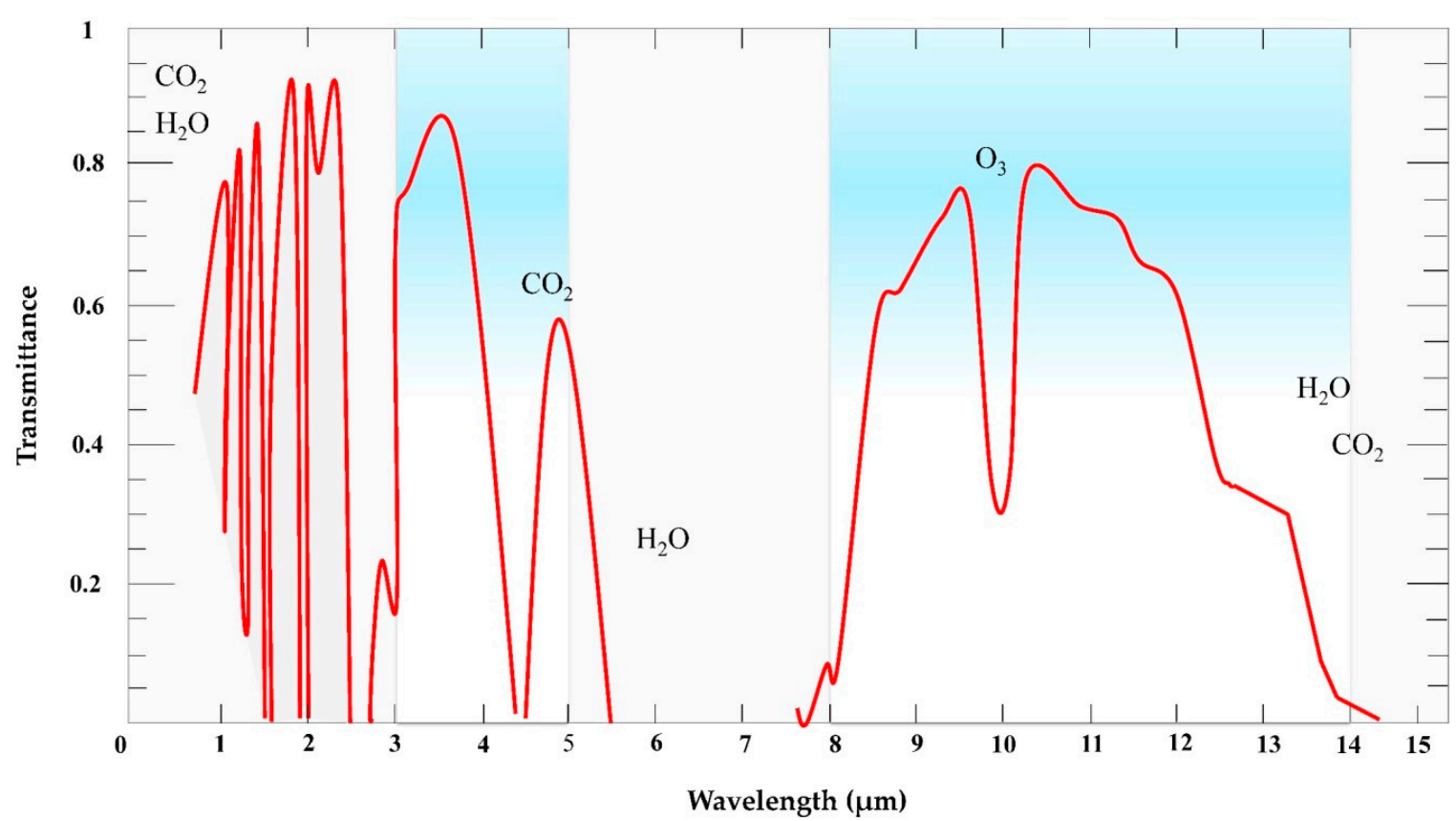

Figure 2. Atmospheric transmittance in the thermal region with typical absorption bands induced by gasses and water (modified from [29]).

The physical laws of Planck, Wien, Stefan-Boltzmann, and Kirchhoff make it possible to better understand the behavior of EM radiation. According to Planck, each energy element (Q) is proportional to its frequency $(v)$, while the Planck's constant $h$ is used to adjust this relationship (Equation (1)):

$$
\mathrm{Q}=\mathrm{h} v
$$


When considering that the frequency of the wave $(v)$ is directly proportional to the speed of light (c) and inversely proportional to its length $(\lambda)$, Equation (1) can be rewritten as follows Equation (2):

$$
\mathrm{Q}=\frac{h c}{\lambda}
$$

In other words, the energy of a quantum is inversely proportional to its wavelength. Thus, the longer the wave (larger wavelength), the lower its energy. Wien's and Boltzmann's laws describe the relationship of a black body's radiations (i.e., an ideal object that absorbs and reemits all of the incident energy) and the wavelength of the maximum emission with a black body's temperature [30].

Wien's displacement law explains the relationship between the true temperature of a black body, being expressed in degrees Kelvin, and its peak spectral exitance or dominant wavelength [27]. As the temperature increases, its maximum exitance shifts towards shorter wavelengths [31]:

$$
\lambda_{\max }=\frac{b}{\mathrm{~T}}
$$

Given that the Wien's constant $b$ is equal to $2898 \mu \mathrm{m} \mathrm{K}$, this formula indicates the wavelength at which the maximum radiant spectral exitance can be obtained. It is possible to observe such effects in nature. For example, a body with a very high absolute temperature like the sun (about $6000 \mathrm{~K}$ ) has a $\lambda_{\max }$ and, thus, a peak of emission in the visible part of the spectrum [32]. The result of the above formula is useful to indicate what should be the measurement range of the sensor used to measure the radiation emitted by a given body [27].

The Stefan-Boltzmann law states that the emittance of a black body is proportional to the fourth power of its absolute temperature (Equation (4)):

$$
\mathrm{E}=\sigma \mathrm{T}^{4}
$$

where E represents the spectral radiant exitance expressed in $W \cdot m^{-2}, \sigma$ is the Stefan-Boltzmann constant, and $\mathrm{T}$ is the absolute temperature $[\mathrm{K}]$. The formula clearly shows that the total EM radiation that is emitted by a black body is a function of its absolute temperature. Therefore, the radiation emitted by a body increases as its temperature increases, as mentioned above.

Kirchhoff's law (1860) (Equation (5)) states that, at a given wavelength, the emittance of a body is equal to its absorption capacity, which is:

$$
\varepsilon=\alpha
$$

where $\varepsilon$ represents the emittance and $\alpha$ the absorbance.

This is frequently formulated as "good absorbers are good emitters and good reflectors are poor emitters" [27]. The principle of energy conservation is defined by the following equation (Equation (6)):

$$
\varepsilon+\rho+\tau=1
$$

where $\rho$ is the reflection and $\tau$ is the transmission. When considering that most objects are opaque to TIR radiation, the above equation becomes (Equation (7)):

$$
\varepsilon+\rho=1
$$

Materials with a high $\varepsilon$ absorb a large quantity of incident energy and radiate large quantities of energy, while materials with low $\varepsilon$ absorb and radiate less energy (Kirchhoff, 1860) [33]. All bodies with a temperature above absolute zero are characterized by random movement-i.e., the kinetic heat, whose measure is the kinetic temperature $\mathrm{T}_{\text {kin }}$ [27]. Besides, an object emits energy as a function of temperature, and the emitted energy is used in order to determine its radiant temperature $T_{\text {rad }}$ [28]. Although there is a strong positive linear correlation between $T_{\text {kin }}$ and $T_{\text {rad }}$, $T_{\text {rad }}$ is lower than $T_{\text {kin }}$ 
due to emissivity $(\varepsilon)$ [34]. For this reason, the temperature that is measured by a sensor $\left(\mathrm{T}_{\mathrm{rad}}\right)$ will always be lower than the real temperature $\left(\mathrm{T}_{\mathrm{kin}}\right)$ (Equation (8)) [31]. It follows from this, as explained by Kirchhoff's law (Equation (8)), that:

$$
\mathrm{T}_{\mathrm{rad}}=\varepsilon^{\frac{1}{4}} \mathrm{~T}^{\mathrm{kin}}
$$

The emissivity is the ratio between the radiation that is emitted by the surface and the radiation emitted by a black body at the same temperature [35]. Because the radiance of any real body, at the same temperature, is always lower than that of a black body (equal to 1), its emissivity has a value between 0 and 1 [27]. Anybody absorbs and emits radiation less effectively at a given temperature when compared to a black body, as explained by Planck's law. Practically, the sensed temperatures of materials with low emissivity appear to be much lower than those of nearby objects with the same temperatures, making the $\mathrm{T}_{\mathrm{kin}}$ assessment less precise [31]. Many factors influence emissivity: color, chemical composition, surface roughness, moisture content, field of view, viewing angle, spectral wavelength, etc. $[27,35,36]$. The emissivity of materials is difficult to measure, although it is more or less constant in the region of the EM that ranges from 8 to $14 \mu \mathrm{m}$. The emissivity of vegetation ranges from 0.96 to 0.99 , while that of soil is around 0.89 , and the emissivity of the water is 0.99 (Table 1 ). In particular, focusing on vegetation, emissivity values of the leaves are available in literature for many plant species $[37,38]$ and some studies were dedicated to the determination of emissivity in herbaceous and tree species $[39,40]$.

Table 1. The emissivity of different surfaces over the range of 8-14 $\mu \mathrm{m}[1,36]$.

\begin{tabular}{cc}
\hline Material & Average Emissivity $(\varepsilon)$ \\
\hline Healthy vegetation & $0.96-0.99$ \\
Dry vegetation & $0.88-0.94$ \\
Wood & $0.93-0.94$ \\
Sand & 0.90 \\
Dry soil & 0.92 \\
Wet soil & $0.95-0.98$ \\
Water & $0.98-0.99$ \\
Snow & $0.98-0.99$ \\
\hline
\end{tabular}

Regarding the intrinsic characteristics of a body, which affect its emissivity, thermal capacity (or heat capacity, measured in $\mathrm{J} \mathrm{kg}^{-1} \mathrm{~K}^{-1}$ ) measures the quantity of heat energy that is necessary for a body to increase its temperature by one degree-the lower the heat capacity, the less energy required. The thermal conductivity (measured in $\mathrm{W} \mathrm{m}^{-1} \mathrm{~K}^{-1}$ ), which measures the rate at which heat passes through a material, is another important parameter. This capacity is greater the higher the value of such a parameter in a material. These parameters can be integrated into the thermal inertia (expressed in $\mathrm{J} \mathrm{m}^{-2} \mathrm{~K}^{-1} \mathrm{~s}^{-\frac{1}{2}}$ ), which measures a body's tendency to change in temperature or the rate of heat transfer between two substances put in contact. This concept is of great importance in the field of TIR, because the capacity of a body to quickly change its temperature (if the thermal inertia is low) depends on this parameter.

\section{Thermal Cameras and Unmanned Aerial Vehicles (UAVs)}

Thermal cameras typically carry a sensor that detects the infrared radiation emitted by a body, displaying its temperature in a digital radiometric image. Two types of thermal cameras are currently available: scanning devices that allow for capturing a point or a line and those with a two-dimensional infrared focal plane array. The latter, which allows for capturing all of the elements of an image at once, is faster if combined with a better image resolution [41] and it is the most commonly used [42]. A further distinction can be made between thermal and photon (or quantum) detectors. The latter convert directly absorbed EM into a change in the distribution of electric energy in a semiconductor by varying 
the concentration of free charge carriers [42] and require a cooling system, usually made while using helium or liquid nitrogen at a temperature of $-196^{\circ} \mathrm{C}$ [27]. The cryocooler lowers the temperature of the sensor with the aim to reduce the thermally induced noise to a level that is lower than that of the signal coming from the image [43]. The more efficient the cooling system, the more accurate the measurements of the instrument, which makes cooled thermal cameras more precise and accurate [44], thus allowing the detection of the slightest temperature differences in the image. These cameras generally work in the mid-wavelength infrared (MWIR) region $(3-8 \mu \mathrm{m})$, where the thermal contrast is high [42]. The thermal radiance of a target is easier to detect once it is distinguishable (higher or lower) from the background [43]. Unfortunately, cooled sensors, besides being large and expensive, have higher energy consumption and they are not suitable for UAVs because of their weight [45]. Thermal detectors are less sensitive $\left( \pm 0.1^{\circ} \mathrm{C}\right)$ and they are slower than quantum detectors, but, instead, have the advantage of not requiring cooling elements [46]. Different types of uncooled detectors are available, all of which are made of different and unconventional materials; the three most common types are VOx (vanadium oxide), amorphous silicon ( $\alpha-\mathrm{Si})$ microbolometers, and ferroelectrics [47]. The operating principle of thermal detectors is based on the conversion of absorbed EM radiation into thermal energy [48]. Ferroelectric detectors are based on the ferroelectric phase transition that can be detected in some dielectric materials. The microbolometer is a resistor organized in arrays-called focal plane arrays, which are made up of VOx and $\alpha-\mathrm{Si}$-which is composed of a thermometer, integrated on a micro-bridge, and an adsorber. Temperature increases, which are caused by absorption of IR radiation, determine large fluctuations of its electrical resistance, which can be converted into electrical signals and processed in order to generate an image [42,49-52], whose geometric resolution depends on the number of detectors. The low values of temperature differences equivalent to noise in uncooled thermal sensors, which reach $20 \mathrm{~m}{ }^{\circ} \mathrm{C}$, allows it to be used in applications where previously only cooled thermal sensors could be used [44]. Furthermore, especially due to the rapid development of micro- and nanotechnology, microbolometers have become cheaper and more efficient [53]. The lenses are made of germanium - a shiny semi-metal, chosen because of its transparency to infrared radiation-and they are reflective of visible radiation [42]. Several parameters characterize a thermal camera; among these, worthy of a mention, include the temperature range measured, usually between -20 and $+120{ }^{\circ} \mathrm{C}$, and the thermal sensitivity, which determines the minimum value of temperature difference $(\Delta \mathrm{T})$ detectable in an image and generally ranges from 40 to $20 \mathrm{~m}{ }^{\circ} \mathrm{C}$ for uncooled and cooled devices, respectively [42]. Regarding the geometric resolution, to date, it is still very low when compared to RGB cameras (currently, higher image resolutions ranging from $320 \times 240$ to $640 \times 512$ pixels), while the spectral resolution normally ranges from 7 to $14 \mu \mathrm{m}$ [12]. As for the price of cameras, their cost can vary from $€ 1.000$ to more than $€ 10,000$, depending on sensor resolution and radiometric calibration accuracy [54,55].

Cooled thermal infrared cameras have the widest use in satellite and aerial RS, thanks to their thermal sensitivity and precision [56]; on the other hand, these devices are larger and more expensive, also in terms of energy, than the uncooled ones [57]. In contrast, uncooled thermal cameras are normally mounted on UAVs (Figure 3a,b), because they are smaller, lighter, and have lower energy consumption [58].

The limited payload is perhaps the principal limit of UAVs, together with the limited battery life, which affects the duration of the flight. For example, it is not unlikely that 45 minutes or more pass between the first and the final image of the dataset when larger areas need to be covered and several flights are required [59].

Payload integration considerably changes between cooled and uncooled TIR cameras, where different ventilation modes are a key factor in image quality; thus, generally, an uncooled microbolometer is preferred for its weight benefits [60]. 

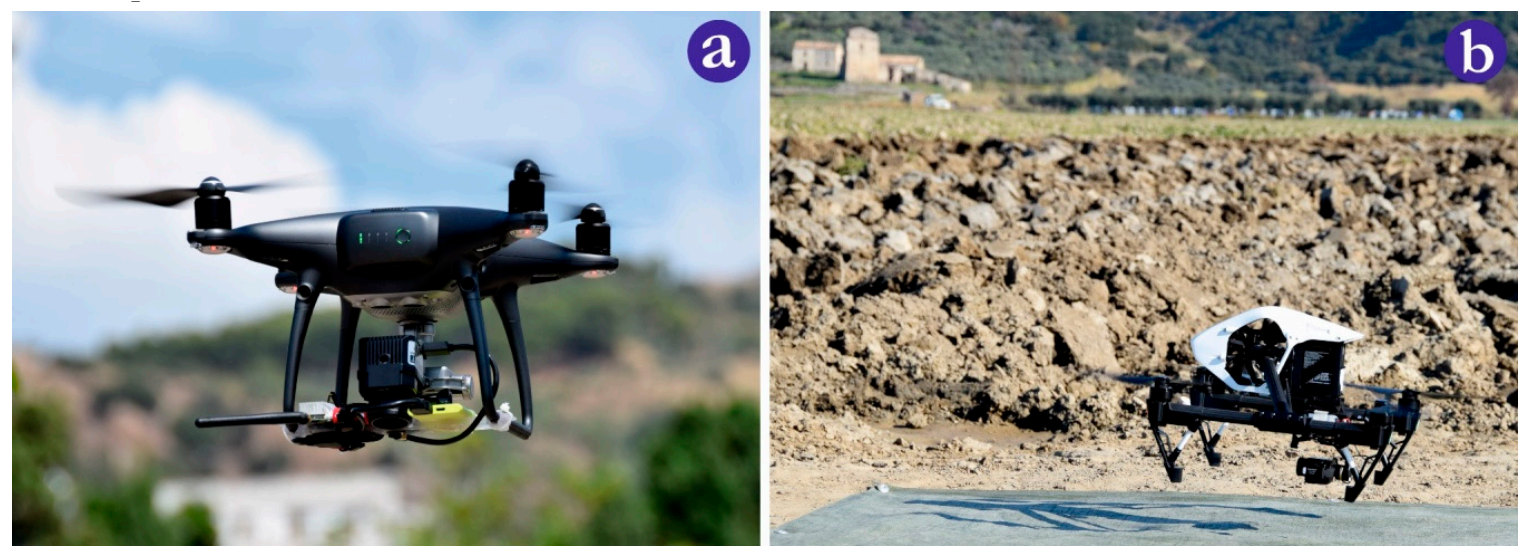

Figure 3. DJI Phantom 4 pro (a) and (b) DJI Inspire 1, both equipped with a FLIR uncooled thermal camera (photos taken by the authors).

\subsection{Camera Calibration and Data Collection}

Low-cost thermal cameras, which are generally not radiometrically calibrated, can only provide information regarding relative temperature differences [54]. The data provided by such instruments are represented in the form of raw digital numbers (DNs) that express radiance. Even when using radiometrically calibrated UAV cameras, it is not easy to derive accurate surface temperature measurements, because their low accuracy is due to the presence of uncooled microbolometers [54]. The sensitivity and, therefore, the accuracy of each microbolometer, is affected by both the temperature of the focal plane array [61] and that of the other components of the thermal camera, body, and lens, such as to create a weak signal-to-noise ratio [53].

Besides this, other causes make it necessary to calibrate a thermal camera, as shown in [53] and [57]. The atmosphere affects the quality of the thermal image as it absorbs and emits IR. The atmospheric effects on UAVs at low-altitude measurements are considered to be negligible when compared to airborne or satellite measurements [31].

The effect of relative humidity, air density, and altitude can only be avoided by making measurements within about $10 \mathrm{~m}$ or less of the target's surface [62]; under different conditions, their effects must be taken into account. Meteorological conditions can have an indirect effect on the temperature measurements of uncooled thermal cameras [59]. In the field, some recommendations are useful for reducing the effects; for instance, the critical factors for data acquisition are the time of day, weather, and the knowledge of the surrounding environment [60]. Regarding the applications in PA, midday has been identified as the best time for flying in terms of thermal accuracy [63] and the reduction of background effects [64].

UAV thermal surveys should always be done in the absence of clouds, rain, snow, smoke, dust, or any other darkening agents, because all of these reduce atmospheric transition, as well as change the temperature of the background [62]. Before the flight, after powering up, the temperature of the camera sensor is expected to stabilize from 20 minutes [25] up to one hour [65]. It is also essential to perform a test flight to allow the camera to acclimatize to local weather conditions, as well as to protect the thermal camera with a casing (to reduce air temperature effects on the sensor) when mounted on a quadcopter UAV [66].

Besides, temperature calibration in the field is an essential step. The temperature of the presumed hottest and coldest objects within the area of image acquisition should be measured for ground truth calibration [31]. Field calibration should be performed while using the thermal measurements of target surfaces during the flight $[20,67]$. These are placed in the area of the study where the temperature is measured using thermocouples [59] or infrared thermo-radiometers [25], combined with data-loggers capable of recording the temperature throughout the flight. Targets can be made using black and white 
polypropylene panels, which represent the thermal extremes of the study site, and whose size is such as to represent several homogeneous pixels in the infrared thermal image [25].

In our experience, as is the case in Messina et al.'s [68] work, wet and dry reference surfaces were used during the thermal UAV survey by taking images of them before and after the flights, as indicated by [59]. Reference surfaces were placed close to UAV take-off and landing points, and their temperature was measured while using a handheld infrared thermometer (FLIR E6) (Figure 6b).

The temperature was measured at three moments of the flight: At take-off, during, and end of every flight. Four reference surfaces were used: three dry panels (black, grey, and white) and one created delimiting a square piece of the ground while using circular targets and covered with aluminum (Figure 4).

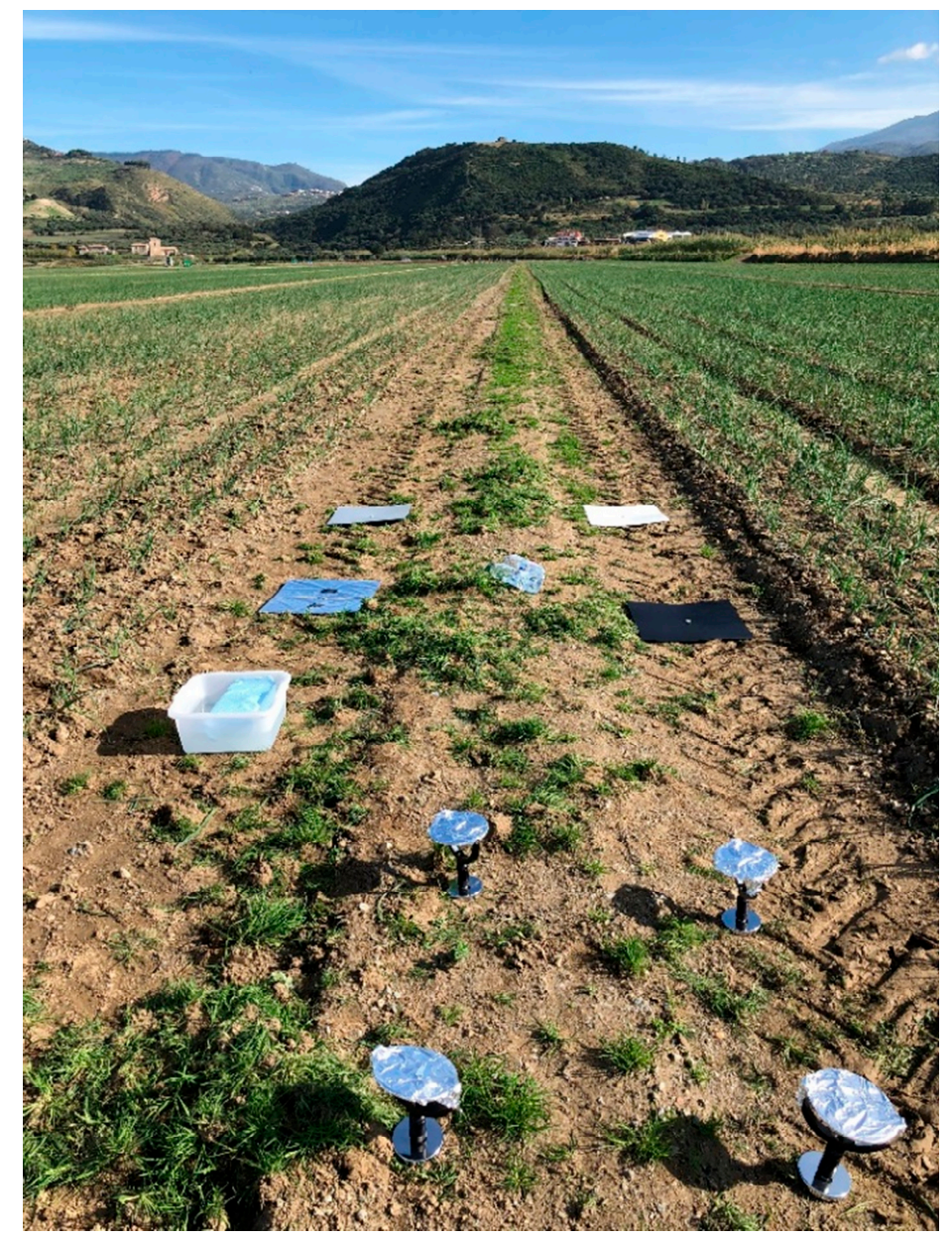

Figure 4. The temperature reference targets used during thermal unmanned aerial vehicle (UAV) surveys in an onion crop field in Calabria (Italy) (photo taken by the authors).

Portions of dry and wet soil can also be considered as targets, as described in the following paragraph. In addition to these, as in the case of multispectral sensors, there are ground control points (GCP)s - points that are marked on the ground that have a known geographical position-which improve the positioning and accuracy of the mapping outputs.

To make GCPs more visible in thermal images, they should have a low emissivity when compared to the adjacent vegetation and other bodies [69].

In the case of thermal measurements, GCPs are made of aluminum, exploiting the low emissivity that makes it appear as a cold object in the images [70] (Figure 5b). This GCP was made using aluminum [71]. Our proposed GCPs were made using $50 \mathrm{~cm} \times 50 \mathrm{~cm}$ white polypropylene panels and covering two quadrants while using aluminum sheets (Figure 5a). Black cardboard was used to 
partially cover the other two quadrants to locate the point and also to make the GCP clearly visible and usable in multispectral surveys (Figure 5c). Figure 5 shows the detectability of the target in thermal and spectral images.
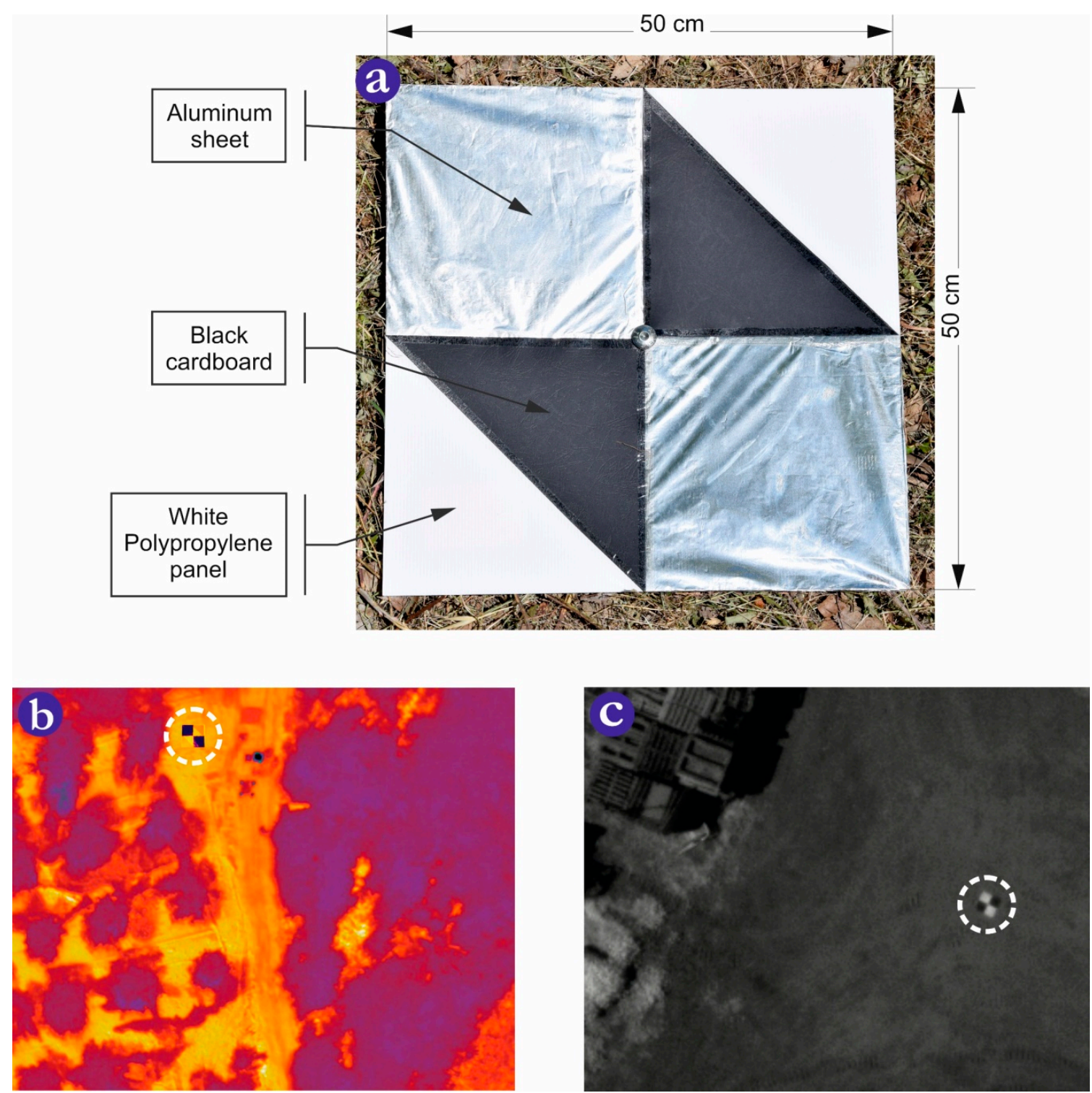

Figure 5. Example of a homemade target for ground control points (GCPs) designed to be easily detected in thermal as well as in multispectral UAV surveys. (a). The GCP target (white dashed circle) as it appears in (b) thermal and (c) near-infrared (NIR) multispectral images.

A further effect of the weather conditions to be taken into account is that of attenuating the thermal radiance by the atmosphere [59]. The sensor registers, for every pixel, an at-sensor radiance ( $\left.\mathrm{L}_{\text {at-sensor }}\right)$, being expressed in $\mathrm{Wm}^{-2}$, which is determined by the following formula (Equation (9)) [72]:

$$
\mathrm{L}_{\mathrm{at}-\mathrm{sensor}}=\tau \mathrm{L}_{\mathrm{surf}}+\mathrm{L}_{\mathrm{atm}}
$$

In Equation (9), $\tau$ represents the atmospheric transmittance, while $\mathrm{L}_{\mathrm{atm}}$, measured in $\mathrm{Wm}^{-2}$, is the upwelling thermal radiation, created as a result of particles in the atmosphere, both depending on the distance of the sensor from the object and the water content in the atmosphere [59]. Parameters $\tau$ and $\mathrm{L}_{\mathrm{atm}}$ can be obtained by exploiting one of the theoretical atmospheric models, such as MODTRAN 
(MODerate resolution atmospheric TRANsmission) [73], which are widely used for thermal data that are acquired from satellites [7]. This model allows for the estimation of atmospheric emission, thermal scattering, and solar scattering by incorporating the effects of molecular absorbers and scatterers, aerosols, and clouds, when considering the wavelengths from the ultraviolet region to the far-infrared [36].

An example of MODTRAN application in UAV is shown by [65], which shows that it allows for obtaining the surface temperature by applying atmospheric correction methods that are based on entering the model as input data, i.e., data that are related to local atmospheric conditions. In the application on UAV data using MODTRAN, it is essential to use local measurements of temperature, relative humidity, and atmospheric pressure acquired from nearby meteorological stations (Figure 6a) placed in the field [39-43].

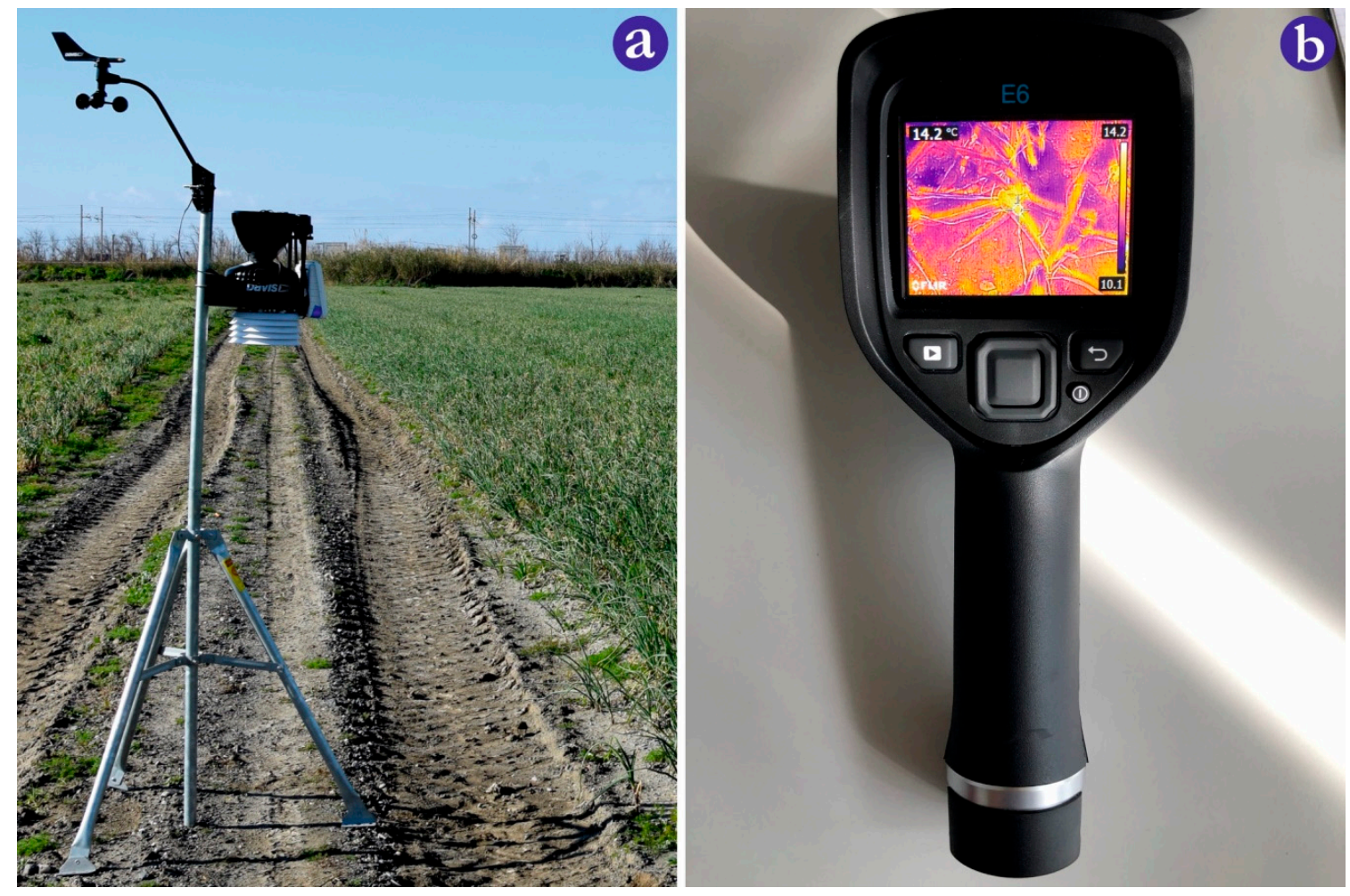

Figure 6. (a) The weather station used during the thermal surveys on an onion field. (b) Handheld infrared thermometer used to measure the temperature of reference surfaces (photos taken by the authors).

\subsection{Data Processing}

Several steps are needed to acquire georeferenced UAV imagery, starting from the flight planning that generates a navigation file guiding the UAV to capture images with the required overlaps and geometric resolution automatically. Thermal imagery can be processed with structure-from-motion (SfM) algorithm, which does not always work properly [59], as reported in [74,75]. Indeed, SfM can be unable to align thermal imagery, making it necessary to mosaic separate images and manually geo-reference them using GCPs. These issues are due to the reduced information contained in the thermal image, which complicates the identification of the common features that are needed for bundle adjustment [59]. Indeed, if compared to other types of imagery, such as RGB, thermal imagery is characterized by a lower geometric resolution and contrast and by a stronger optical distortion [69]. In addition to increasing vertical and horizontal overlaps, the presence of an incorporated multispectral (or RGB) camera, which is characterized by a higher geometric resolution, could help the alignment step of the photogrammetric process. A framework to process thermal imagery is shown in Turner et al.'s [76] 
study. Firstly, image pre-processing provided the removal of blurry imagery and the subsequent conversion of images to a 16-bit file format. In this way, all of the images have the same dynamic scale, and a specific temperature value corresponds to the same digital number (DN) in all images. Secondly, image alignment was executed using GPS log files and the imagery's time stamps. Finally, the spatial image was co-registered to RGB images. Some improvements of this framework were provided in [59] in order to optimize the alignment and processing of thermal images by exploiting the increased information contained in the RGB data. Although recent UAV models are provided with real-time kinematic global navigation satellite systems (RTK-GNSS) that are able to reach a centimeter planimetric accuracy, to ensure high positional precision, the placement of GCP within the surveyed site is generally expected. Imagery must be geometrically aligned (orthorectification), calibrated, and corrected, while taking atmospheric effects into account before final orthomosaics are obtained [7] (Figure 7).
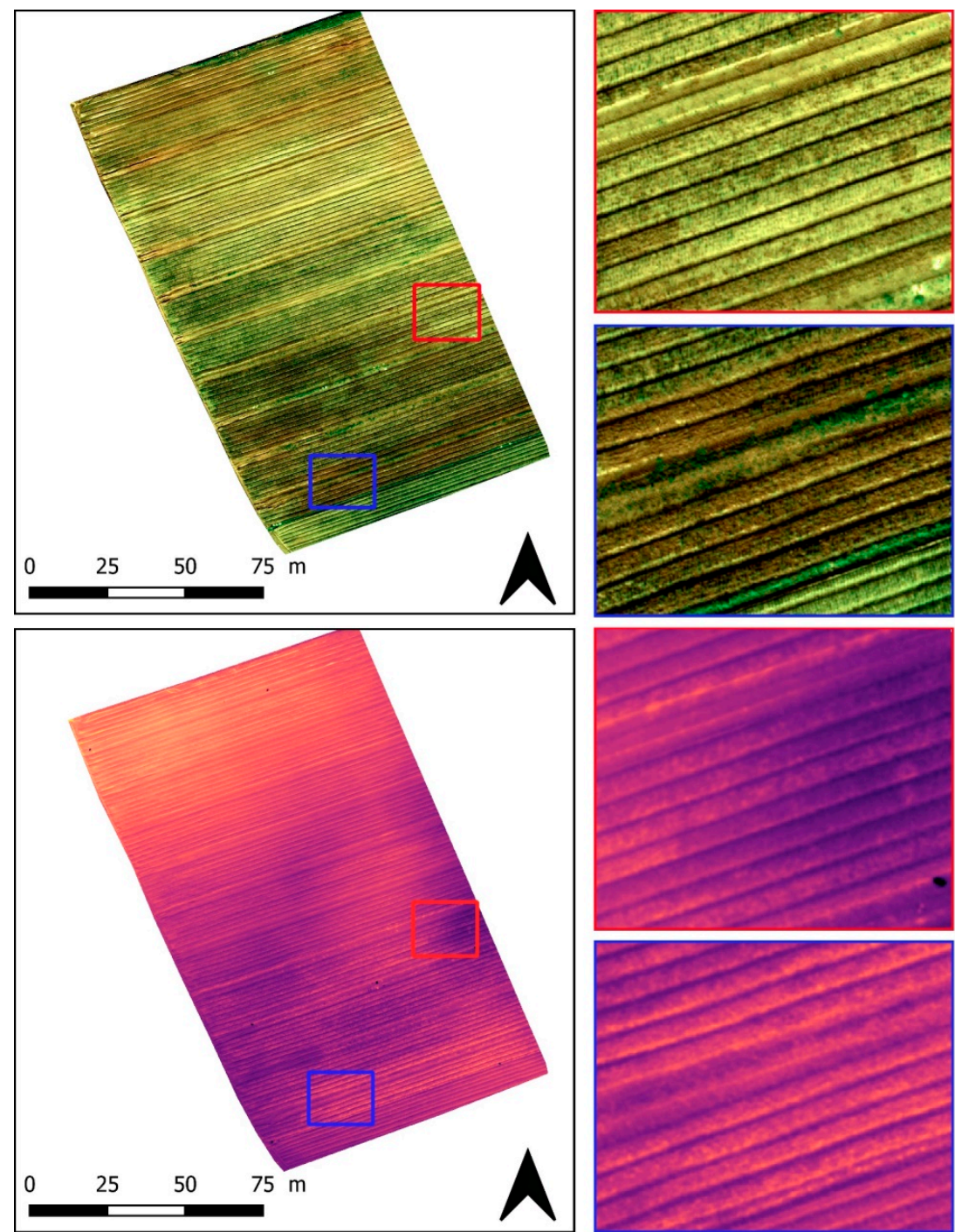

\section{Temperature $\left[{ }^{\circ} \mathrm{C}\right]$}

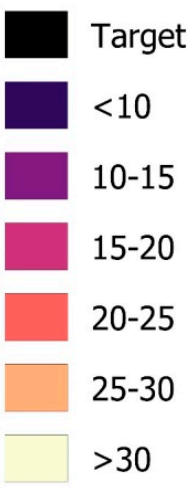

Figure 7. RGB (top) and thermal orthomosaic (bottom) images of an onion field (data collected by the authors). 


\section{Thermal UAV Imagery Analysis and Applications in Precision Agriculture (PA)}

\subsection{Crop water Stress Monitoring}

Several detection systems have been developed for the production of specialty crops worldwide thanks to technological advances [77]. The collection of accurate information on the spatial variability of fields is essential in this context. A field's variability is affected by several factors, including crop yield and water content, and sensors that can be used to detect these factors include thermal cameras.

Plant water stress is one of the main critical factors of abiotic stress, as it limits the development of crops [78,79]. Therefore, among the applications of thermal UAV RS in agriculture, the identification of water stress from plant temperature data is of great importance, with irrigation resource management being a key issue for PA. The use of UAVs in the study of plant water status requires measurements of stem water potential $\left(\psi_{\mathrm{s}}\right)$ and stomatal conductance $\left(\mathrm{g}_{\mathrm{s}}\right)$, which are the most common physiological water stress indicators that are used to determine crop water status [15,76,80,81]. Both indicators can be measured in the field while using a pressure chamber and porometers, respectively, although the interpolation of such local observations is not straightforward.

The use of thermal images allows for detecting the water stress conditions of a plant, because, at the foliar level, stomata closure reduces transpiration and evaporative cooling, which results in an increased temperature of the leaf $[82,83]$. This increase in temperature can be detected by thermal cameras; therefore, thermal images can provide spatially continuous information concerning the water status of plants in a wider area than that obtained by local measurements $[84,85]$. The temperature of the plant is not only regulated by the water supply, but also by the micrometeorological conditions [86]. Among the climatic factors, atmospheric humidity plays a crucial role and, in environments with humid climates, cloudiness also becomes a critical factor [87]. Several indices have been developed in the past decades with the aim of compensating for the variation of these conditions [86].

The CWSI was developed precisely for that purpose. Jackson and colleagues formulated the CWSI while using portable IR thermometers on herbaceous crops [84,88], developing a normalized index in order to overcome environmental effects that may affect the relationship between plant temperature and water stress. This index, which can assume values that range between 0 and 1, results in being directly proportional to the water stress level of many species of interest. The CWSI is based on the normalization of the canopy-air temperature difference with evaporative demand by means of the vapor pressure deficit (VPD) of the air [14]. The formula to calculate the CWSI is as follows, according to the methodology that was proposed by Idso et al. [17] (Equation (10)):

$$
\text { CWSI }=\frac{\left(\mathrm{T}_{C}-\mathrm{T}_{a}\right)-\left(\mathrm{T}_{C}-\mathrm{T}_{a}\right) \mathrm{LL}}{\left(\mathrm{T}_{\mathrm{C}}-\mathrm{T}_{a}\right) \mathrm{UL}-\left(\mathrm{T}_{\mathrm{C}}-\mathrm{T}_{a}\right) \mathrm{LL}}
$$

Where $T_{c}-T_{a}$ is the canopy-air temperature difference, while LL refers to the $T_{c}-T_{a}$ values for the lower limit and UL for the upper limit. The normalization related to the VPD considers the $T_{c}-T_{a}$ difference of a canopy under two boundary conditions: (a) a lower limit when it transpires at its potential rate (i.e., under well-watered conditions), and (b) an upper limit under no transpiration. The lower limit is described by linear regression between $T_{c}-T_{a}$ and the VPD, which is known as the non-water-stressed baseline (NWSB). The NWSB is empirically derived by measuring the leaf-air temperature difference for a well-watered crop in the experimental environment and provides the lowest temperature difference likely in that environment. Once the NWSB, (Tc - Ta)LL can be calculated by solving the baseline equation for the current VPD. The upper limit (Tc - Ta)UL, which is a constant, is obtained by solving the same NWSB equation for a hypothetical slightly negative VPD. It represents the vapor pressure difference that is generated by the temperature differential $(\mathrm{Tc}-\mathrm{Ta}$ ) when VPD is 0 [17]. The upper limit value is close to the NWSB interception $a$ (depending on the temperature) and only corresponds to $a$ when $a$ is equal to 0 [89]. This method is site-dependent. A second approach for obtaining the upper and lower limits of (Tc - Ta) is theoretical and it foresees the combination of energy balance and diffusion equations. This method requires knowledge of challenging to obtain variables, 
such as net radiation and aerodynamic resistance [19,89]. Another approach, defined statistical, was used with good results $[15,63,90,91]$. In brief, it foresees the use of the average temperature of the most cooling $5-10 \%$ of the canopy pixels as the wet reference to calculate the lower limit [92].

A further method that was proposed to obtain the two limits consists in the use of direct measurements over wet or dry reference surfaces, natural or artificial. The reference dry targets, as suggested by Jones [93,94], can be achieved, impeding leaf transpiration by covering the leaf surface (on one or both sides) with petroleum jelly. In this case, the temperature of the upper limit reference results from the measurement of the leaf temperature carried out about 30 minutes after the application of the petroleum jelly layer. The wet targets are obtained by spraying a thin layer of water on one or both leaf sides before taking the thermal image-this is valid on a single plant scale [94]. The advantage of using this method is that the stress levels are normalized to the actual response of the plants. However, the need to repeat the measurement for each test site after each flight of the UAV can be an obstacle to its applicability. In addition, another problem is related to the difficulty of identifying the leaves that are covered by petroleum jelly $[95,96]$. Maes proposed an example of a wet artificial reference target in [97] using a cloth and a steel wireframe. The target thus created, with an appearance, shape, and size similar to kiwi and grapevines leaves was kept wet for days by keeping the lower part of the cloth immersed inside a bottle filled with water. Artificial targets were also used in [98]. This study provides an approach in which the reference temperature of the upper limit is set at $5{ }^{\circ} \mathrm{C}$ above the air temperature, while that of the lower limit is derived from the temperature of the artificial target. Berni et al. [19] proposed an approach to monitor relatively large areas while using UAVs to detect water stress; the work, focused on the control of water stress in an olive grove, based on physical models for the estimation of input variables of energy balance equations, did not require the use of reference surfaces.

Two problems have prevented the widespread use of the CWSI: the first concerns its use under changing atmospheric conditions, and the second occurs when using lower resolution data from satellites or aircrafts platforms (as compared to UAVs), concerning, namely, the problem of "mixed-pixel value", which is where part of the temperature of the pixel comes from the background soil and not from the pure canopy, thus reducing the quality of the data [99].

As far as the first aspect is concerned, CWSI was found to work better in dry climates, while it showed considerable limitations in wet climates and in environments with substantial climatic variability [100]. In fact, it must be taken into account that the absolute in leaf-air temperature difference decreases as the atmospheric humidity deficit decreases, and the same goes for sensitivity to any measurements made. Furthermore, while taking the latter aspect into account in the calculation of the CWSI, as the humidity (and temperature) deficit decreases, the signal-to-noise ratio is reduced [101]. Finally, it must also be considered that the canopy temperature depends, in part, on variations in the roughness of the canopy, wind speed, and net radiation, all of which are more variable in humid climates [87].

As far as the problem of "mixed-pixel value" is concerned, while the resolution of satellite images is limited, the sensors mounted on UAVs, because of their sub-meter spatial resolution, make it easier to recover the pure canopy temperature while minimizing the thermal effects of the background soil $[65,102,103]$. Different approaches can be adopted, as shown in [99]. An approach to extracting the temperatures of canopies' sunlit leaves foresees distinguishing canopies' pixels from background pixels that are based on an analysis of the temperature distribution among the pixel population and then segment the image into two distinct classes. This solution is possible where there is a clear difference between the average temperature of the canopy and that of the soil/background. A valid solution also includes the use of additional information that is derived from RGB, multispectral and hyperspectral images (in cases where several sensors are used simultaneously), in order to identify plant's pixels [99]. In this case, the use of vegetation indices, like NDVI, to separate soil pixels and plant pixels can be useful. 
In addition to the CWSI, several normalized thermal indices were developed between the 1970s and 1980s. Among these, there are the conductance index (IG) and the stomatal conductance index (I3), whose formulas (Equations (11) and (12)) are as follows:

$$
\begin{array}{r}
I G=\frac{\mathrm{T}_{d r y}-\mathrm{T}_{C}}{\mathrm{~T}_{C}-\mathrm{T}_{\text {wet }}} \\
I 3=\frac{\mathrm{T}_{C}-\mathrm{T}_{\text {wet }}}{\mathrm{T}_{d r y}-\mathrm{T}_{C}}
\end{array}
$$

where $T_{c}$ represents the surface temperature of the canopy, while $T_{d r y}$ and $T_{\text {wet }}$ are entirely dry or wet reference surfaces to simulate leaf temperature under conditions of minimum and maximum transpiration.

The main aspects of these two indices are that IG increases with stomatal conductance, while I3 is positively correlated with stomatal resistance [94,96]. The three indices (CWSI, IG, and I3) need the knowledge of canopy temperature under both wet and dry conditions; however, the concept of the CWSI remains the most widely used, as it is best known [94].

Research carried out thus far has concerned the monitoring of water stress in both herbaceous and tree crops. In Sullivan et al.'s [24] and Bian et al.'s [104] research, thermal UAVs were used, respectively, to monitor Gossypium hirsutum L. crop residue management and the response to different irrigation treatments, calculating the CWSI. Martinez et al. [105] worked on monitoring sugar beet water stress by comparing thermal data, which were obtained using a conventional thermal camera, with those obtained using a low-cost infrared sensor.

Zhang et al. [106] monitored, at the farm scale, maize water stress using RGB and thermal images. The study of Crusiol et al. [107] dealt with the evaluation of the water status of soybean plants under different water conditions. Other works $[108,109]$ focused on the monitoring of herbaceous crops while using different sensors (RGB, multispectral, and thermal) with the aim of producing orthomosaics and vigor maps.

The CWSI is also widely used for perennial crops. Bellvert et al. [110] calculated the index in peach trees (Prunus Persica), mapping the internal spatial variability of the orchard by thermal UAV and verifying the relationships between the index and the leaf water potential in different growing seasons. Gonzalez-Dugo et al. [91] studied the spatial variations in the water status of five different fruit tree species: almond (Prunus dulcis), apricot (Prunus armeniaca), peach (Prunus persica), lemon (Citrus $x$ limon), and orange (Citrus sinensis). In this respect, it is important to remember that the stomatal response to environmental conditions can vary from species to species [111]. Olive and citrus show relevant stomatal closure at midday $[89,91]$, while, in other species, such as almond trees, the stomatal behavior changes between the different cultivars [112].

Some studies have applied thermal UAV RS to citrus orchards (orange, Citrus sinensis, and mandarin, Citrus reticulata) in order to extract the temperature of the crowns for water stress detection $[113,114]$. Research has also been carried out on olive crops, a species of great importance in the countries of the Mediterranean basin [115], in order to verify the plant's behavior in response to various irrigation treatments. In particular, Poblete-Echeverría et al. [116] showed that the temperature difference between the canopy $\left(\mathrm{T}_{\mathrm{c}}\right)$ and air $\left(\mathrm{T}_{\mathrm{a}}\right)$ is related to the difference in water potential under different irrigation treatments when the plants are under water stress conditions. Berni et al. [19] used very high-resolution UAV thermal imagery to calculate and map the tree canopy conductance and the CWSI in a heterogeneous olive orchard.

Egea et al. [117] demonstrated the usefulness of the CWSI for monitoring water stress in a dense olive orchard by verifying sound relationships between the index and water stress indicators, such as stomatal conductance, stem water potential, and leaf transpiration rate. Ortega-Farías et al. [118], while using thermal and multispectral cameras that were mounted on UAVs, estimated the energy 
balance components on a drip irrigation olive grove, acquiring high-resolution images to evaluate intra-field spatial variability.

Several works have used thermal UAVs for the calculation of the CWSI in vineyards, such as that of Zarco-Tejada et al. [81]. In Baluja et al.'s [15] study, the relationships between the temperatures or indices that were derived from thermal and multispectral imagery and stomatal conductance and water potential were determined. In particular, air and leaf temperatures were recorded with a handheld thermometer, and stomatal conductance was measured with a leaf gas exchange system, while the stem water potential was measured using a Scholander pressure bomb; the CWSI, IG, and I3 indices were also calculated.

Similarly, the work by Bellvert et al. [20] related the CWSI with leaf water potential and that by Santesteban et al. [119] related the CWSI with stem water potential and seasonal leaf stomatal conductance to estimate the variability of plant water status in a vineyard. Matese et al. [120] and Pàdua et al. [16,121] exploited the use of different sensors (RGB, multispectral, and thermal) for several applications in precision viticulture: the production of vigor maps, multi-temporal analysis of vigor maps, and water stress detection. Gómez-Candón et al. [25], by testing in an apple orchard, proposed a methodology to derive thermal orthomosaics, including a method for the radiometric correction of thermal UAV imagery.

\subsection{Plant Disease Detection, Phenotyping, Yield Estimation, and Vegetation Status Monitoring}

Calderón et al. provides an interesting example of application in the framework of plant pathology of thermal UAV RS [14]. In particular, this research aimed to evaluate the use of thermal imagery and physiological indices derived from other types of sensors to detect the presence of infection that is caused by the soil-borne fungus Verticillium dahliae. The role of thermal RS in the diagnosis of the pathology is due to the water stress of plants, caused by the fungus, or by the stomatal closure, which determines the reduction of the transpiration rate. Therefore, decreasing evaporative cooling increases leaf temperature. By conducting field measurements, it was demonstrated that crown variations of temperature are higher and stomatal conductance lower as the severity level of the disease increased. Besides, crown temperature and the CWSI index were shown to be among the best indicators to detect Verticillium dahliae in the early stages of disease development.

With regard to the issue of yield estimation and related aspects, thermal UAV RS was exploited to research cotton, soybean, and rice crops [23,122,123]. Feng et al. [122] used three types of sensors (RGB, multispectral, and thermal) in order to analyze several features to see which one had the best performance for the yield prediction and at which stages of the crop cycle: Four vegetation indices, canopy cover, plant height, temperature, and a cotton fiber index.

The study of Maimaitijiang et al. [123] on soybean concerned testing the potentialities of using different sensors (including the thermal camera) in the framework of multimodal data fusion and deep neural network to derive useful information for the yield prediction model. Liu et al. [23] investigated rice lodging while using RGB and thermal sensor UAV images. The objectives of the research were to measure the daily temperature differences between non-lodged and lodged rice crops, as well as to detect the optimal time window. Because the differences in temperature between 10 a.m. and 4 p.m. were significant, thermal camera devices allowed for identifying lodged rice plants.

Some other works have focused on the monitoring of vineyards and related landscape elements, such as agricultural terraces [124-127]. In particular, Tucci et al. [125,126] used RGB and thermal cameras to investigate the thermal dynamics of a vineyard that was grown on dry-stone wall terraced land. These dry-stone terraces are part of the UNESCO's Representative List of the Intangible Cultural Heritage of Humanity and are typical and iconic features of the agricultural landscapes across Europe, including Italy [128]. However, the risk of abandonment and degradation threaten agricultural terraces, which can involve the increase of hazards that are linked to geo-hydrological processes triggered by rainfall events. In this framework, the use of RGB and thermal sensors mounted on UAVs represents an efficient and cost-effective monitoring methodology, also given the high resolution of the images 
and the reduced time for their acquisition. Tucci et al. [125], besides verifying the effectiveness of the used sensors in monitoring the terraced crops, investigated the influence that dry-stone walls can have on the microclimate of the vineyard and, consequently, on the quality of the obtained grapes. The results of the study showed differences in the temperature between the plants of the internal rows (lower temperatures) and the external rows (higher temperatures).

Phenotyping has an important role in crop science research. The acquisition of crop phenotypic information in different environments allows the association of genomic and phenotypic information useful for increasing yield [129]. In this framework, recently, the importance of the use of UAVs has increased, as they provide a rapid and non-destructive approach to phenotyping, also allowing the use of high spatial resolution images [129,130].

The use of UAVs has made it possible to overcome various limits that are linked to the use of traditional methods, such as the difficulty in making simultaneous measurements on different plots [131]. In this context, some works have been carried out involving the use of thermal UAV RS, thus proving its effectiveness, as in [9]. Natarajan et al. [132] employed different sensors (visible, multispectral, and thermal) that were mounted on UAVs for the phenotyping of indirect traits (including canopy temperature) for early-stage selection in sugarcane breeding.

Gracia-Romero et al.'s [133] work concerned the comparison of the performance of RGB, multispectral, and thermal data, which were derived from ground-based and UAV surveys, with the aim to assess genotypic differences in durum wheat's yield, under different growing conditions. In this case, the measurement of the canopies' temperature was an alternative valid to that of leaf stomatal conductance. Perich et al. [134] exploited thermal UAV RS to measure canopy temperature in wheat. Canopy temperature has a strong association with water status and stomatal conductance in wheat [135-137]; in particular, low canopy temperature can be associated with a 30\% increase in yield, as well as an increase in water absorption by the deeper roots when measured during the grain filling phase [138]. Maimaitijiang et al.'s [139] study, which was performed on soybean, showed that the fusion of thermal and multispectral data could provide the best estimate of the biochemical traits of crops (chlorophyll content and N concentration) and biophysics (LAI, fresh and dry biomass).

The use of thermal UAV RS has proven to be very promising as a less-expensive way for mapping drainage systems. Subsurface tile drainage is of great importance in the Midwest of the United States [140]. Subsoil drainage allows for the level of groundwater to be lowered by removing excess water, as well as reducing soil erosion and increasing the aeration [141,142] and infiltration capacity of water derived from precipitation.

Knowing the precise layout of the drainage networks, as well as bringing benefits for their better functionality, favors soil and water conservation practices [143]. Additional benefits include increases in the soil productivity and yield of the crops, most of which do not tolerate excess water [143-145]. As the soil is directly above a drainage line, it is often drier than the soil between the drainage lines [146]. Differences in emissivity between dry and wet soil surfaces can be detected while using a thermal camera [147], which has been demonstrated in several studies using thermal cameras mounted on UAVs, even in combination with visible and multispectral cameras, showing the significant performance of thermal images and potentialities for their use in mapping agricultural drainage pipe systems [143,146,148-150].

Table 2 reports the dataset of all analyzed studies concerning the application of thermal UAV RS in precision agriculture (PA) and organized based on the aim of the study, the type of the used camera sensor, and the analyzed crops. 
Table 2. Dataset compilation of studies concerning the application of thermal UAV remote sensing (RS) in precision agriculture (PA).

\begin{tabular}{|c|c|c|c|}
\hline Aim of the Study & Camera Sensor & Analyzed Crops & References \\
\hline Water stress detection and plant phenotyping & Thermal & Soybean and sorghum & [9] \\
\hline Water stress and disease detection & Thermal / Multispectral / Hyperspectral & Olive & [14] \\
\hline Water stress detection & Thermal / Multispectral & Grapevine & [15] \\
\hline \multirow{4}{*}{ Water stress detection and monitoring } & Thermal / Multispectral / RGB & Grapevine & [16] \\
\hline & Thermal / Multispectral & Olive & [19] \\
\hline & Thermal & Grapevine & [20] \\
\hline & Thermal & Sugar beet & [21] \\
\hline Monitoring lodging & Thermal / RGB & Rice & [23] \\
\hline Irrigation and crop residue management & Thermal & Cotton & [24] \\
\hline Water stress detection & Thermal / Multispectral / RGB & Apple & [25] \\
\hline Monitoring and water stress detection & Thermal / Multispectral & Cotton, Corn, Olive and Peach & [65] \\
\hline \multirow{3}{*}{ Monitoring } & Thermal / Multispectral & Onion & [68] \\
\hline & Thermal / Multispectral & Barley and Corn & [108] \\
\hline & Thermal / RGB & Grapevine & {$[125,126]$} \\
\hline Evapotranspiration estimation & Thermal & - & [74] \\
\hline \multirow{13}{*}{ Water stress detection } & Thermal & Nectarine and Peach & [70] \\
\hline & Thermal / Multispectral & Grapevine & [81] \\
\hline & Thermal & $\begin{array}{l}\text { Almond, Apricot, Peach, } \\
\text { Orange, Lemon }\end{array}$ & [91] \\
\hline & Thermal / Multispectral & Cotton & [104] \\
\hline & Thermal & Sugar beet & [105] \\
\hline & Thermal / RGB & Corn & [106] \\
\hline & Thermal / RGB & Soybean & [107] \\
\hline & Thermal / Multispectral & Soybean & [109] \\
\hline & Thermal & Nectarine and Peach & [110] \\
\hline & Thermal / Hyperspectral & Mandarin and Orange & [113] \\
\hline & Thermal / Hyperspectral & Grapevine & [114] \\
\hline & Thermal & Grapevine and Olive & {$[116,117]$} \\
\hline & Thermal & Grapevine & {$[119,120]$} \\
\hline Estimation of energy balance components & Thermal / Multispectral & Olive & [118] \\
\hline Monitoring and water stress detection & Thermal / Multispectral / RGB & Grapevine & [121] \\
\hline \multirow{3}{*}{ Yield estimation } & Thermal / Multispectral / RGB & Cotton & [122] \\
\hline & Thermal / Multispectral / RGB & Soybean & [123] \\
\hline & Thermal / Multispectral & Grapevine & [127] \\
\hline \multirow{4}{*}{ Phenotyping } & Thermal / Multispectral / RGB & Sugarcane & [132] \\
\hline & Thermal / Multispectral / RGB & Wheat & [133] \\
\hline & Thermal & Wheat & [134] \\
\hline & Thermal / Multispectral & Soybean & [139] \\
\hline \multirow{2}{*}{ Mapping drainage systems } & Thermal / RGB & - & [143] \\
\hline & Thermal / Multispectral / RGB & Corn and soybean & {$[146,148,149]$} \\
\hline
\end{tabular}

\section{Conclusions and Future Research Outlook}

This review covered the state-of-the-art thermal UAV RS technology and, to the best of our knowledge, is the first to deal with this topic. We also outlined an overview of the latest applications of thermal UAV RS in the framework of PA. Starting from a synthesis of the fundamental principles of thermography, necessary for the less experienced who approach this scientific field, this was followed by a brief description of the features of thermal cameras, from the operation of the sensor that allows the conversion of measurements into images to a hint about the cameras' cost, briefly covering the topics of field data acquisition, calibration, and data processing.

As far as the application of thermal UAV RS in agriculture is concerned, a literature review made it possible to verify the presence of numerous works devoted to the subject. To the best 
of our knowledge, most of the applications of thermal UAV RS have concerned the detection of crops water stress and the management of irrigation resources-both being crucial aspects for crop development and agriculture $[12,83,151]$. The other applications, in a smaller number, have dealt with the identification of symptoms that are caused by pathologies, phenotyping, monitoring, yield estimation, and the identification of drainage networks in the fields.

Certainly, the use of UAV thermal sensors is not as widespread as that of other sensors, such as optical and multispectral sensors, and this is probably due to the characteristics of thermal sensors and the type of data that are derived from them. Although the first aspect is important, an important limitation of thermal cameras is their geometric resolution, which is low when compared to, for example, RGB sensors. The second concerns the data that are derived from the sensor, i.e., the temperature, which has proved to be fundamental in the detection of water stress in plants, given the natural mechanisms that regulate the temperature of plants. Excluding, perhaps, this type of application, which sees thermal sensors as protagonists and advantageous over other sensors, especially for the possibility of detecting water stress connections in advance, other types of applications that have provided the exclusive use of thermal cameras are not many, especially when considering the field of plant pathology. The real potential of cameras on UAVs can be exploited at high levels and with maximum profit in terms of utility, focusing on the feature that makes UAVs unique: that of being able to simultaneously mount and use multiple sensors [152]. The thermal camera used side-by-side with RGB and multispectral sensors can increase the importance of UAVs in PA and expand their possibilities in terms of use. In particular, when considering, for example, plant pathology, in order to improve the ability to detect diseases or parasitic attacks at an early stage, the use of different sensors, including thermal sensors, and the fusion/combination of their derived data with optical and multispectral sensors, should be considered [153]. The possibility to perform surveys with a centimeter resolution, coupling different sensors at any time, and with more affordable costs, puts UAVs ahead of aircraft platforms. When compared to satellites, on the other hand, the introduction of platforms, including nanosatellites, equipped with sensors, capable of offering high-resolution images of less than $3 \mathrm{~m}$ or the ultra-high resolution of less than $1 \mathrm{~m}$ makes satellites increasingly competitive with regard to drones in PA applications [152,154-157]. It would be interesting to combine thermal (and optical) satellite data with UAV data, together with data that were collected on the ground, as shown, for example, in [109]. As things stand, when considering the different platforms and sensors of RS, no one is probably able to offer a high resolution in all spatial, spectral, and temporal dimensions [153]. Therefore, it would be desirable to synergize UAV images with high-resolution satellite images to improve the quality of the final products, including thermal RS, in order to overcome these limits.

Naturally, new developments are also expected in the framework of thermal RS. Likewise, it is also expected that the current trend of increasing user-friendliness for all types of users will continue in the technological development of UAVs and sensors. Greater automation, where possible, of aspects that are related to both the field data acquisition phase (preparation of the optimal flight plan, configuration, and calibration of the sensors before and during flight) and the data processing phase (together with the reduction of the time that is needed for data processing) is necessary as the next steps to implement the use of UAVs in agriculture. As far as ground data acquisition is concerned, as explained in the previous paragraphs, it remains an essential step for the moment. Specifically for thermal RS, a simpler and more easy and immediate combination of the data that were collected by weather stations with data derived from UAVs would be useful. Indeed, there are still important practical difficulties in the correct collection of data, when considering the mitigation of atmospheric effects, calibration, climatic conditions, and the complex interactions between soil and plants [7]-particularly true in the case of thermal RS, whose raw data before the processing steps are far from offering true and accurate temperature measurements. In this respect, thermal RS requires accurate knowledge of thermography [152] in all its application phases, from the preparation of the surveys to the final product. If this aspect, on the one hand, does not fail to stimulate the world 
of research to explore all aspects of thermal RS, then it might, on the other hand, constitute a limit for use outside this field.

However, it is fair to say that, given the important progress in the use of RS sensors in agriculture, in the short term, new solutions should also be able to simplify and expand the use of thermal RS in agriculture and PA, increasing its integration in decision making [7]. PA needs high-intensity procedures for the use of acquired images and it requires the presence of experienced and qualified personnel [126], which results in higher costs for companies. Therefore, the use of advanced technologies, including the use of UAVs, remains confined to those farmers with large agricultural areas available [158]. This aspect is more evident in the case of thermal UAV surveys, when considering that their operational costs per hectare are higher than those of multispectral surveys [159].

Author Contributions: Conceptualization, methodology, investigation, data curation, writing-review and editing, G.M. (Gaetano Messina) and G.M. (Giuseppe Modica). All authors have read and agreed to the published version of the manuscript.

Funding: This research received no external funding.

Acknowledgments: The authors are grateful to DR-One S.r.l. (http://www.dr-onesrl.com-Belmonte Calabro, Cosenza, Italy) for providing UAV thermal surveys. The authors would like to express their great appreciation to the three anonymous reviewers for their very constructive comments provided during the revision of the paper, and that contributes to improving it significantly.

Conflicts of Interest: The authors declare no conflicts of interest.

\section{References}

1. Lillesand, T.; Kiefer, R.W.; Chipman, J. Remote Sensing and Image Interpretation, 7th ed.; Wiley and sons: New York, NY, USA, 2015; ISBN 978-1-118-91947-7.

2. Pajares, G. Overview and Current Status of Remote Sensing Applications Based on Unmanned Aerial Vehicles (UAVs). Photogramm. Eng. Remote Sens. 2015, 81, 281-330. [CrossRef]

3. Chen, S.; Laefer, D.F.; Mangina, E. State of Technology Review of Civilian UAVs. Recent Patents Eng. 2016, 10, 160-174. [CrossRef]

4. Nex, F.; Remondino, F. UAV for 3D mapping applications: A review. Appl. Geomat. 2014, 6, 1-15. [CrossRef]

5. Shakhatreh, H.; Sawalmeh, A.; Al-Fuqaha, A.; Dou, Z.; Almaita, E.; Khalil, I.; Othman, N.S.; Khreishah, A.; Guizani, M. Unmanned Aerial Vehicles: A Survey on Civil Applications and Key Research Challenges. arXiv 2018, arXiv:1805.00881, 1-58. [CrossRef]

6. Zhang, C.; Kovacs, J.M. The application of small unmanned aerial systems for precision agriculture: A review. Precis. Agric. 2012, 13, 693-712. [CrossRef]

7. Khanal, S.; Fulton, J.; Shearer, S. An overview of current and potential applications of thermal remote sensing in precision agriculture. Comput. Electron. Agric. 2017, 139, 22-32. [CrossRef]

8. Anderson, M.C.; Hain, C.; Otkin, J.; Zhan, X.; Mo, K.; Svoboda, M.; Wardlow, B.; Pimstein, A. An Intercomparison of Drought Indicators Based on Thermal Remote Sensing and NLDAS-2 Simulations with U.S. Drought Monitor Classifications. J. Hydrometeorol. 2013, 14, 1035-1056. [CrossRef]

9. Sagan, V.; Maimaitijiang, M.; Sidike, P.; Eblimit, K.; Peterson, K.; Hartling, S.; Esposito, F.; Khanal, K.; Newcomb, M.; Pauli, D.; et al. UAV-Based High Resolution Thermal Imaging for Vegetation Monitoring, and Plant Phenotyping Using ICI 8640 P, FLIR Vue Pro R 640, and thermoMap Cameras. Remote Sens. 2019, 11, 330. [CrossRef]

10. Ludovisi, R.; Tauro, F.; Salvati, R.; Khoury, S.; Mugnozza, G.S.; Harfouche, A. Uav-based thermal imaging for high-throughput field phenotyping of black poplar response to drought. Front. Plant Sci. 2017, 8, 1-18. [CrossRef]

11. Costa, J.M.; Grant, O.M.; Chaves, M.M. Thermography to explore plant-environment interactions. J. Exp. Bot. 2013, 64, 3937-3949. [CrossRef]

12. Gago, J.; Douthe, C.; Coopman, R.E.; Gallego, P.P.; Ribas-Carbo, M.; Flexas, J.; Escalona, J.; Medrano, H. UAVs challenge to assess water stress for sustainable agriculture. Agric. Water Manag. 2015, 153, 9-19. [CrossRef]

13. Radoglou-Grammatikis, P.; Sarigiannidis, P.; Lagkas, T.; Moscholios, I. A compilation of UAV applications for precision agriculture. Comput. Netw. 2020. [CrossRef] 
14. Calderón, R.; Navas-Cortés, J.A.; Lucena, C.; Zarco-Tejada, P.J. High-resolution airborne hyperspectral and thermal imagery for early detection of Verticillium wilt of olive using fluorescence, temperature and narrow-band spectral indices. Remote Sens. Environ. 2013, 139, 231-245. [CrossRef]

15. Baluja, J.; Diago, M.P.; Balda, P.; Zorer, R.; Meggio, F.; Morales, F.; Tardaguila, J. Assessment of vineyard water status variability by thermal and multispectral imagery using an unmanned aerial vehicle (UAV). Irrig. Sci. 2012, 30, 511-522. [CrossRef]

16. Pádua, L.; Marques, P.; Adão, T.; Guimarães, N.; Sousa, A.; Peres, E.; Sousa, J.J. Vineyard variability analysis through UAV-based vigour maps to assess climate change impacts. Agronomy 2019, 9, 581. [CrossRef]

17. Idso, S.B.; Jackson, R.D.; Pinter, P.J.; Reginato, R.J.; Hatfield, J.L. Normalizing the stress-degree-day parameter for environmental variability. Agric. Meteorol. 1981, 24, 45-55. [CrossRef]

18. Alderfasi, A.A.; Nielsen, D.C. Use of crop water stress index for monitoring water status and scheduling irrigation in wheat. Agric. Water Manag. 2001, 47, 69-75. [CrossRef]

19. Berni, J.A.J.; Zarco-Tejada, P.J.; Sepulcre-Cantó, G.; Fereres, E.; Villalobos, F. Mapping canopy conductance and CWSI in olive orchards using high resolution thermal remote sensing imagery. Remote Sens. Environ. 2009, 113, 2380-2388. [CrossRef]

20. Bellvert, J.; Zarco-Tejada, P.J.; Girona, J.; Fereres, E. Mapping crop water stress index in a "Pinot-noir" vineyard: Comparing ground measurements with thermal remote sensing imagery from an unmanned aerial vehicle. Precis. Agric. 2014, 15, 361-376. [CrossRef]

21. Quebrajo, L.; Perez-Ruiz, M.; Pérez-Urrestarazu, L.; Martínez, G.; Egea, G. Linking thermal imaging and soil remote sensing to enhance irrigation management of sugar beet. Biosyst. Eng. 2018, 165, 77-87. [CrossRef]

22. Romano, G.; Zia, S.; Spreer, W.; Sanchez, C.; Cairns, J.; Araus, J.L.; Müller, J. Use of thermography for high throughput phenotyping of tropical maize adaptation in water stress. Comput. Electron. Agric. 2011, 79, 67-74. [CrossRef]

23. Liu, T.; Li, R.; Zhong, X.; Jiang, M.; Jin, X.; Zhou, P.; Liu, S.; Sun, C.; Guo, W. Estimates of rice lodging using indices derived from UAV visible and thermal infrared images. Agric. For. Meteorol. 2018, 252, 144-154. [CrossRef]

24. Sullivan, D.G.; Fulton, J.P.; Shaw, J.N.; Bland, G. Evaluating the sensitivity of an unmanned thermal infrared aerial system to detect water stress in a cotton canopy. Trans. ASABE 2007, 50, 1963-1969. [CrossRef]

25. Gómez-Candón, D.; Virlet, N.; Labbé, S.; Jolivot, A.; Regnard, J.L. Field phenotyping of water stress at tree scale by UAV-sensed imagery: New insights for thermal acquisition and calibration. Precis. Agric. 2016, 17, 786-800. [CrossRef]

26. Prakash, A. Thermal Remote Sensing: Concepts, issues and applications. Int. Arch. Photogramm. Remote Sens. 2000, 33, 239-243.

27. Jensen, J.R. Remote Sensing of the Environment: An Earth Resource Perspective, 2nd ed.; Pearson: Harlow, UK, 2014; Volume 1, ISBN 9780131889507.

28. Vinet, L.; Zhedanov, A. A “missing” family of classical orthogonal polynomials. Geogr. J. 2010, 146, 448. [CrossRef]

29. Richter, R.; Schlapfer, D. Atmospheric and Topographic Correction: Model ATCOR3. Aerospace 2019, 3, 1-144.

30. Walker, J.; Halliday, D.; Resnick, R. Fundamentals of Physics, 10th ed.; Wiley: New York, NY, USA, 2015; ISBN 9781118230725.

31. Kuenzer, C.; Dech, S.; Zhang, J.; Jing, L.; Huadong, G. Thermal infrared remote sensing: Sensors, Methods, Applications. In Remote Sensing and Digital Image Processing; Springer: Heidelberg, Germany, 2013; Volume 17.

32. Kuenzer, C.; Zhang, J.; Jing, L.; Huadong, G.; Dech, S. Thermal infrared remote sensing of surface and underground coal fires. In Remote Sensing and Digital Image Processing; Springer: Heidelberg, Germany, 2013; Volume 17, pp. 429-451.

33. Sabin, F. Remote Sensing: Principles and Interpretation, (Floyd F. Sabins); W.H.Freeman \& Co: New York, NY, USA, 1997; ISBN 0716724421.

34. Schmugge, T.; French, A.; Ritchie, J.C.; Rango, A.; Pelgrum, H. Temperature and emissivity separation from multispectral thermal infrared observations. Remote Sens. Environ. 2002, 79, 189-198. [CrossRef]

35. Jacob, F.; Petitcolin, F.; Schmugge, T.; Vermote, É.; French, A.; Ogawa, K. Comparison of land surface emissivity and radiometric temperature derived from MODIS and ASTER sensors. Remote Sens. Environ. 2004, 90, 137-152. [CrossRef]

36. Campbell e Wynne. Introduction to Remote Sensing; The Guiford Press: New York, NY, USA, 2017; ISBN 9781609181765. 
37. Salisbury, J.W.; D'Aria, D.M. Emissivity of terrestrial materials in the 8-14 $\mu \mathrm{m}$ atmospheric window. Remote Sens. Environ. 1992, 42, 83-106. [CrossRef]

38. Gates, D.M.; Keegan, H.J.; Schleter, J.C.; Weidner, V.R. Spectral Properties of Plants. Appl. Opt. 1965, 4, 11. [CrossRef]

39. Chen, C. Determining the leaf emissivity of three crops by infrared thermometry. Sensors 2015, 15, 11387-11401. [CrossRef] [PubMed]

40. López, A.; Molina-Aiz, F.D.; Valera, D.L.; Peña, A. Determining the emissivity of the leaves of nine horticultural crops by means of infrared thermography. Sci. Hortic. 2012, 137, 49-58. [CrossRef]

41. Kaplan, H. Practical Applications of Infrared Thermal Sensing and Imaging Equipment, 3rd ed.; SPIE: Bellingham, WA, USA, 2007; ISBN 9780819479020.

42. Gade, R.; Moeslund, T.B. Thermal cameras and applications: A survey. Mach. Vis. Appl. 2014, 25, $245-262$. [CrossRef]

43. FLIR. Tech Note: Cooled Versus Uncooled Cameras for Long Range Surveillance; FLIR: Breda, The Netherlands, 2011.

44. Mesas-Carrascosa, F.J.; Pérez-Porras, F.; Meroño de Larriva, J.; Mena Frau, C.; Agüera-Vega, F.; Carvajal-Ramírez, F.; Martínez-Carricondo, P.; García-Ferrer, A. Drift Correction of Lightweight Microbolometer Thermal Sensors On-Board Unmanned Aerial Vehicles. Remote Sens. 2018, 10, 615. [CrossRef]

45. Jensen, A.M.; McKee, M.; Chen, Y. Procedures for processing thermal images using low-cost microbolometer cameras for small unmanned aerial systems. Int. Geosci. Remote Sens. Symp. 2014, 2629-2632. [CrossRef]

46. Luhmann, T.; Piechel, J.; Roelfs, T. Geometric calibration of thermographic cameras. Remote Sens. Digit. Image Process. 2013, 17, 27-42. [CrossRef]

47. Sizov, F.F. IR region challenges: Photon or thermal detectors? Outlook and means. Semicond. Phys. Quantum Electron. Optoelectron. 2015, 15, 193-199. [CrossRef]

48. Hyseni, G.; Caka, N.; Hyseni, K. Infrared thermal detectors parameters: Semiconductor bolometers versus pyroelectrics. WSEAS Trans. Circuits Syst. 2010, 9, 238-247.

49. Bhan, R.K.; Saxena, R.S.; Jalwania, C.R.; Lomash, S.K. Uncooled infrared microbolometer arrays and their characterisation techniques. Def. Sci. J. 2009, 59, 580-589. [CrossRef]

50. Fièque, B.; Tissot, J.L.; Trouilleau, C.; Crastes, A.; Legras, O. Uncooled microbolometer detector: Recent developments at Ulis. Infrared Phys. Technol. 2007, 49, 187-191. [CrossRef]

51. Bieszczad, G.; Kastek, M. Measurement of thermal behavior of detector array surface with the use of microscopic thermal camera. Metrol. Meas. Syst. 2011, 18, 679-690. [CrossRef]

52. FLIR. Tech Note: Uncooled Detectors for Thermal Imaging Cameras; FLIR: Breda, The Netherlands, 2015.

53. Budzier, H.; Gerlach, G. Calibration of uncooled thermal infrared cameras. J. Sens. Sens. Syst. 2015, 4, 187-197. [CrossRef]

54. Kelly, J.; Kljun, N.; Olsson, P.-O.; Mihai, L.; Liljeblad, B.; Weslien, P.; Klemedtsson, L.; Eklundh, L. Challenges and best practices for deriving temperature data from an uncalibrated UAV thermal infrared camera. Remote Sens. 2019, 11, 567. [CrossRef]

55. Manfreda, S.; McCabe, M.F.; Miller, P.E.; Lucas, R.; Madrigal, V.P.; Mallinis, G.; Dor, E.B.; Helman, D.; Estes, L.; Ciraolo, G.; et al. On the use of unmanned aerial systems for environmental monitoring. Remote Sens. 2018, 10, 641. [CrossRef]

56. Sheng, H.; Chao, H.; Coopmans, C.; Han, J.; McKee, M.; Chen, Y. Low-cost UAV-based thermal infrared remote sensing: Platform, calibration and applications. In Proceedings of the 2010 IEEE/ASME International Conference on Mechatronic and Embedded Systems and Applications, Qingdao, China, 15-17 July 2010; pp. 38-43.

57. Ribeiro-Gomes, K.; Hernández-López, D.; Ortega, J.; Ballesteros, R.; Poblete, T.; Moreno, M. Uncooled Thermal Camera Calibration and Optimization of the Photogrammetry Process for UAV Applications in Agriculture. Sensors 2017, 17, 2173. [CrossRef]

58. Gallo, M.A.; Willits, D.S.; Lubke, R.A.; Thiede, E.C. Low-cost uncooled IR sensor for battlefield surveillance. In Proceedings of the SPIE: International Symposium on Optic, Imaging, and Instrumentation, San Diego, CA, USA, 11-16 July 1993; Andresen, B.F., Shepherd, F.D., Eds.; Volume 2020, p. 351.

59. Maes, W.; Huete, A.; Steppe, K. Optimizing the Processing of UAV-Based Thermal Imagery. Remote Sens. 2017, 9, 476. [CrossRef]

60. Stark, B.; Smith, B.; Chen, Y. Survey of thermal infrared remote sensing for Unmanned Aerial Systems. In Proceedings of the 2014 International Conference on Unmanned Aircraft Systems (ICUAS), Orlando, FL, USA, 27-30 May 2014; pp. 1294-1299. [CrossRef] 
61. Olbrycht, R.; Wiecek, B.; De Mey, G. Thermal drift compensation method for microbolometer thermal cameras. Appl. Opt. 2012, 51, 1788-1794. [CrossRef]

62. FLIR. Tech Note: Radiometric Temperature Measurements Surface Characteristics and Atmospheric Compensation; FLIR: Breda, The Netherlands, 2012.

63. Alchanatis, V.; Cohen, Y.; Cohen, S.; Moller, M.; Sprinstin, M.; Meron, M.; Tsipris, J.; Saranga, Y.; Sela, E. Evaluation of different approaches for estimating and mapping crop water status in cotton with thermal imaging. Precis. Agric. 2010, 11, 27-41. [CrossRef]

64. Sepulcre-Cantó, G.; Zarco-Tejada, P.J.; Jiménez-Muñoz, J.C.; Sobrino, J.A.; De Miguel, E.; Villalobos, F.J. Detection of water stress in an olive orchard with thermal remote sensing imagery. Agric. For. Meteorol. 2006, 136, 31-44. [CrossRef]

65. Berni, J.; Zarco-Tejada, P.J.; Suarez, L.; Fereres, E. Thermal and Narrowband Multispectral Remote Sensing for Vegetation Monitoring From an Unmanned Aerial Vehicle. IEEE Trans. Geosci. Remote Sens. 2009, 47, 722-738. [CrossRef]

66. Kelly, J.; Eklundh, L.; Kljun, N. Radiometric Calibration of a UAV Thermal Camera. Available online: https://pdfs.semanticscholar.org/3c00/560ae50c9c34187904dcb01af863a7c3088c.pdf (accessed on 1 March 2020).

67. Dupin, S.; Gobrecht, A.; Tisseyre, B. Tisseyre Airborne Thermography of Vines Canopy: Effect of the Atmosphere and Mixed Pixels on Observed Canopy Temperature. 8 Conf. Eur. Agric. Precis. 2011, 1, 1-9.

68. Messina, G.; Praticò, S.; Siciliani, B.; Curcio, A.; Di Fazio, S.; Modica, G. Monitoring onion crops using UAV multispectral and thermal imagery. In Conference AIIA Mid-Term 2019 Biosystems Engineering for Sustainable Agriculture, Forestry and Food Production, Matera, Italy, 12-13 September 2019; Springer: Cham, Switzerland, 2019.

69. Boesch, R. Thermal remote sensing with UAV-based workflows. Int. Arch. Photogramm. Remote Sens. Spat. Inf. Sci. 2017, 42, 41-46. [CrossRef]

70. Park, S.; Ryu, D.; Fuentes, S.; Chung, H.; Hernández-Montes, E.; O'Connell, M. Adaptive estimation of crop water stress in nectarine and peach orchards using high-resolution imagery from an unmanned aerial vehicle (UAV). Remote Sens. 2017, 9, 828. [CrossRef]

71. Chio, S.H.; Lin, C.H. Preliminary study of UAS equipped with thermal camera for volcanic geothermal monitoring in Taiwan. Sensors 2017, 17, 1649. [CrossRef]

72. Maes, W.H.; Pashuysen, T.; Trabucco, A.; Veroustraete, F.; Muys, B. Does energy dissipation increase with ecosystem succession? Testing the ecosystem exergy theory combining theoretical simulations and thermal remote sensing observations. Ecol. Modell. 2011, 222, 3917-3941. [CrossRef]

73. Berk, A.; Anderson, G.P.; Acharya, P.K.; Chetwynd, J.H.; Bernstein, L.S.; Shettle, E.P.; Matthew, M.W.; Adler-Golden, S. MODTRAN4 User's manual. In Hanscom AFB; Air Force Res. Lab.: MA, USA, 1999; Available online: ftp://ftp.pmodwrc.ch/pub/Vorlesung\%20K+S/MOD4_user_guide.pdf (accessed on 1 March 2020).

74. Hoffmann, H.; Nieto, H.; Jensen, R.; Guzinski, R.; Zarco-Tejada, P.; Friborg, T. Estimating evaporation with thermal UAV data and two-source energy balance models. Hydrol. Earth Syst. Sci. 2016, 20, 697-713. [CrossRef]

75. Pech, K.; Stelling, N.; Karrasch, P.; De, H.M. Generation of Multitemporal Thermal Orthophotos From UAV Data. Int. Arch. Photogramm. Remote Sens. 2013, 1, 4-6. [CrossRef]

76. Turner, D.; Lucieer, A.; Malenovský, Z.; King, D.H.; Robinson, S.A. Spatial co-registration of ultra-high resolution visible, multispectral and thermal images acquired with a micro-UAV over antarctic moss beds. Remote Sens. 2014, 6, 4003-4024. [CrossRef]

77. Lee, W.S.; Alchanatis, V.; Yang, C.; Hirafuji, M.; Moshou, D.; Li, C. Sensing technologies for precision specialty crop production. Comput. Electron. Agric. 2010, 74, 2-33. [CrossRef]

78. Gerhards, M.; Rock, G.; Schlerf, M.; Udelhoven, T. Water stress detection in potato plants using leaf temperature, emissivity, and reflectance. Int. J. Appl. Earth Obs. Geoinf. 2016, 53, 27-39. [CrossRef]

79. Gautam, D.; Pagay, V. A review of current and potential applications of remote sensing to study thewater status of horticultural crops. Agronomy 2020, 10, 140. [CrossRef]

80. Ballester, C.; Zarco-Tejada, P.J.; Nicolás, E.; Alarcón, J.J.; Fereres, E.; Intrigliolo, D.S.; Gonzalez-Dugo, V. Evaluating the performance of xanthophyll, chlorophyll and structure-sensitive spectral indices to detect water stress in five fruit tree species. Precis. Agric. 2017, 1-16. [CrossRef]

81. Zarco-Tejada, P.J.; González-Dugo, V.; Williams, L.E.; Suárez, L.; Berni, J.A.J.; Goldhamer, D.; Fereres, E. A PRI-based water stress index combining structural and chlorophyll effects: Assessment using diurnal narrow-band airborne imagery and the CWSI thermal index. Remote Sens. Environ. 2013, 138, 38-50. [CrossRef] 
82. Hsiao, T.C. Plants response to water stress. Ann. Rev. Plant Physiol. 1973, 24, 519-570. [CrossRef]

83. Gerhards, M.; Schlerf, M.; Mallick, K.; Udelhoven, T. Challenges and future perspectives of multi-/Hyperspectral thermal infrared remote sensing for crop water-stress detection: A review. Remote Sens. 2019, 11, 1240. [CrossRef]

84. Jackson, R.D.; Idso, S.B.; Reginato, R.J.; Pinter, J.P.J. Canopy temperature as a crop water stress indicator. Water Resour. Res. 1981, 17, 1133-1138. [CrossRef]

85. Lapidot, O.; Ignat, T.; Rud, R.; Rog, I.; Alchanatis, V.; Klein, T. Use of thermal imaging to detect evaporative cooling in coniferous and broadleaved tree species of the Mediterranean maquis. Agric. For. Meteorol. 2019, 271, 285-294. [CrossRef]

86. Gerhards, M.; Schlerf, M.; Rascher, U.; Udelhoven, T.; Juszczak, R.; Alberti, G.; Miglietta, F.; Inoue, Y. Analysis of airborne optical and thermal imagery for detection of water stress symptoms. Remote Sens. 2018, 10, 1139. [CrossRef]

87. Jones, H.G. Thermal imaging and infrared sensing in plant ecophysiology. Adv. Plant Ecophysiol. Tech. 2018, 135-151. [CrossRef]

88. Cohen, Y.; Alchanatis, V.; Meron, M.; Saranga, Y.; Tsipris, J. Estimation of leaf water potential by thermal imagery and spatial analysis. J. Exp. Bot. 2005, 56, 1843-1852. [CrossRef] [PubMed]

89. Testi, L.; Goldhamer, D.A.; Iniesta, F.; Salinas, M. Crop water stress index is a sensitive water stress indicator in pistachio trees. Irrig. Sci. 2008, 26, 395-405. [CrossRef]

90. Rud, R.; Cohen, Y.; Alchanatis, V.; Levi, A.; Brikman, R.; Shenderey, C.; Heuer, B.; Markovitch, T.; Dar, Z.; Rosen, C.; et al. Crop water stress index derived from multi-year ground and aerial thermal images as an indicator of potato water status. Precis. Agric. 2014, 15, 273-289. [CrossRef]

91. Gonzalez-Dugo, V.; Zarco-Tejada, P.; Nicolás, E.; Nortes, P.A.; Alarcón, J.J.; Intrigliolo, D.S.; Fereres, E. Using high resolution UAV thermal imagery to assess the variability in the water status of five fruit tree species within a commercial orchard. Precis. Agric. 2013, 14, 660-678. [CrossRef]

92. Cohen, Y.; Alchanatis, V.; Saranga, Y.; Rosenberg, O.; Sela, E.; Bosak, A. Mapping water status based on aerial thermal imagery: Comparison of methodologies for upscaling from a single leaf to commercial fields. Precis. Agric. 2017, 18, 801-822. [CrossRef]

93. Jones, H.G. Use of infrared thermometry for estimation of stomatal conductance as a possible aid to irrigation scheduling. Agric. For. Meteorol. 1999, 95, 139-149. [CrossRef]

94. Maes, W.H.; Steppe, K. Estimating evapotranspiration and drought stress with ground-based thermal remote sensing in agriculture: A review. J. Exp. Bot. 2012, 63, 4671-4712. [CrossRef]

95. Jones, H.G.; Serraj, R.; Loveys, B.R.; Xiong, L.; Wheaton, A.; Price, A.H. Thermal infrared imaging of crop canopies for the remote diagnosis and quantification of plant responses to water stress in the field. Funct. Plant Biol. 2009, 36, 978-989. [CrossRef]

96. Maes, W.H.; Achten, W.M.J.; Reubens, B.; Muys, B. Monitoring stomatal conductance of Jatropha curcas seedlings under different levels of water shortage with infrared thermography. Agric. For. Meteorol. 2011, 151, 554-564. [CrossRef]

97. Maes, W.H.; Baert, A.; Huete, A.R.; Minchin, P.E.H.; Snelgar, W.P.; Steppe, K. A new wet reference target method for continuous infrared thermography of vegetations. Agric. For. Meteorol. 2016, 226-227, 119-131. [CrossRef]

98. Agam, N.; Cohen, Y.; Berni, J.A.J.; Alchanatis, V.; Kool, D.; Dag, A.; Yermiyahu, U.; Ben-Gal, A. An insight to the performance of crop water stress index for olive trees. Agric. Water Manag. 2013, 118, 79-86. [CrossRef]

99. Jones, H.; Sirault, X. Scaling of Thermal Images at Different Spatial Resolution: The Mixed Pixel Problem. Agronomy 2014, 4, 380-396. [CrossRef]

100. Hipps, L.E.; Asrar, G.; Kanemasu, E.T. A theoretically-based normalization of environmental effects on foliage temperature. Agric. For. Meteorol. 1985, 35, 113-122. [CrossRef]

101. Jones, H.G.; Vaughan, R.A. Remote Sensing of Vegetation Principles, Techniques, and Applications; Oxford University Press: Oxford, UK, 2010; ISBN 9780199207794.

102. Herwitz, S.R.; Johnson, L.F.; Dunagan, S.E.; Higgins, R.G.; Sullivan, D.V.; Zheng, J.; Lobitz, B.M.; Leung, J.G.; Gallmeyer, B.A.; Aoyagi, M.; et al. Imaging from an unmanned aerial vehicle: Agricultural surveillance and decision support. Comput. Electron. Agric. 2004, 44, 49-61. [CrossRef]

103. Sugiura, R.; Noguchi, N.; Ishii, K. Remote-sensing technology for vegetation monitoring using an unmanned helicopter. Biosyst. Eng. 2005, 90, 369-379. [CrossRef] 
104. Bian, J.; Zhang, Z.; Chen, J.; Chen, H.; Cui, C.; Li, X.; Chen, S.; Fu, Q. Simplified Evaluation of Cotton Water Stress Using High Resolution Unmanned Aerial Vehicle Thermal Imagery. Remote Sens. 2019, 11, 267. [CrossRef]

105. Martínez, J.; Egea, G.; Agüera, J.; Pérez-Ruiz, M. A cost-effective canopy temperature measurement system for precision agriculture: A case study on sugar beet. Precis. Agric. 2017, 18, 95-110. [CrossRef]

106. Zhang, L.; Niu, Y.; Zhang, H.; Han, W.; Li, G.; Tang, J.; Peng, X. Maize Canopy Temperature Extracted From UAV Thermal and RGB Imagery and Its Application in Water Stress Monitoring. Front. Plant Sci. 2019, 10, 1-18. [CrossRef]

107. Crusiol, L.G.T.; Nanni, M.R.; Furlanetto, R.H.; Sibaldelli, R.N.R.; Cezar, E.; Mertz-Henning, L.M.; Nepomuceno, A.L.; Neumaier, N.; Farias, J.R.B. UAV-based thermal imaging in the assessment of water status of soybean plants. Int. J. Remote Sens. 2020, 41, 3243-3265. [CrossRef]

108. Raeva, P.L.; Šedina, J.; Dlesk, A. Monitoring of crop fields using multispectral and thermal imagery from UAV. Eur. J. Remote Sens. 2019, 52, 192-201. [CrossRef]

109. Sagan, V.; Maimaitiyiming, M.; Sidike, P.; Maimaitiyiming, M.; Erkbol, H.; Peterson, K.T.; Peterson, J.; Burken, J.; Fritschi, F. UAV/Satellite Multiscale Data Fusion for Crop Monitoring and Early Stress Detection. Int. Arch. Photogramm. Remote Sens. Spat. Inf. Sci. 2019. [CrossRef]

110. Bellvert, J.; Marsal, J.; Girona, J.; Gonzalez-Dugo, V.; Fereres, E.; Ustin, S.L.; Zarco-Tejada, P.J. Airborne thermal imagery to detect the seasonal evolution of crop water status in peach, nectarine and Saturn peach orchards. Remote Sens. 2016, 8, 39. [CrossRef]

111. Ballester, C.; Jiménez-Bello, M.A.; Castel, J.R.; Intrigliolo, D.S. Usefulness of thermography for plant water stress detection in citrus and persimmon trees. Agric. For. Meteorol. 2013, 168, 120-129. [CrossRef]

112. Gonzalez-Dugo, V.; Zarco-Tejada, P.; Berni, J.A.J.; Suárez, L.; Goldhamer, D.; Fereres, E. Almond tree canopy temperature reveals intra-crown variability that is water stress-dependent. Agric. For. Meteorol. 2012, 154-155, 156. [CrossRef]

113. Gonzalez-Dugo, V.; Zarco-Tejada, P.J.; Fereres, E. Applicability and limitations of using the crop water stress index as an indicator of water deficits in citrus orchards. Agric. For. Meteorol. 2014, 198-199, 94-104. [CrossRef]

114. Zarco-Tejada, P.J.; González-Dugo, V.; Berni, J.A.J. Fluorescence, temperature and narrow-band indices acquired from a UAV platform for water stress detection using a micro-hyperspectral imager and a thermal camera. Remote Sens. Environ. 2012, 117, 322-337. [CrossRef]

115. Solano, F.; Di Fazio, S.; Modica, G. Int J Appl Earth Obs Geoinformation A methodology based on GEOBIA and WorldView-3 imagery to derive vegetation indices at tree crown detail in olive orchards. Int J. Appl. Earth Obs. Geoinf. 2019, 83, 101912. [CrossRef]

116. Poblete-Echeverría, C.; Sepulveda-Reyes, D.; Ortega-Farias, S.; Zuñiga, M.; Fuentes, S. Plant water stress detection based on aerial and terrestrial infrared thermography: A study case from vineyard and olive orchard. Acta Hortic. 2016, 1112, 141-146. [CrossRef]

117. Egea, G.; Padilla-Díaz, C.M.; Martinez-Guanter, J.; Fernández, J.E.; Pérez-Ruiz, M. Assessing a crop water stress index derived from aerial thermal imaging and infrared thermometry in super-high density olive orchards. Agric. Water Manag. 2017, 187, 210-221. [CrossRef]

118. Ortega-Farías, S.; Ortega-Salazar, S.; Poblete, T.; Kilic, A.; Allen, R.; Poblete-Echeverría, C.; Ahumada-Orellana, L.; Zuñiga, M.; Sepúlveda, D. Estimation of Energy Balance Components over a Drip-Irrigated Olive Orchard Using Thermal and Multispectral Cameras Placed on a Helicopter-Based Unmanned Aerial Vehicle (UAV). Remote Sens. 2016, 8, 638. [CrossRef]

119. Santesteban, L.G.; Di Gennaro, S.F.; Herrero-Langreo, A.; Miranda, C.; Royo, J.B.; Matese, A. High-resolution UAV-based thermal imaging to estimate the instantaneous and seasonal variability of plant water status within a vineyard. Agric. Water Manag. 2017, 183, 49-59. [CrossRef]

120. Matese, A.; Baraldi, R.; Berton, A.; Cesaraccio, C.; Di Gennaro, S.F.; Duce, P.; Facini, O.; Mameli, M.G.; Piga, A.; Zaldei, A. Estimation of Water Stress in grapevines using proximal and remote sensing methods. Remote Sens. 2018, 10, 114. [CrossRef]

121. Pádua, L.; Adão, T.; Sousa, A.; Peres, E.; Sousa, J.J. Individual Grapevine Analysis in a Multi-Temporal Context Using UAV-Based Multi-Sensor Imagery. Remote Sens. 2020, 12, 139. [CrossRef]

122. Feng, A.; Zhou, J.; Vories, E.D.; Sudduth, K.A.; Zhang, M. Yield estimation in cotton using UAV-based multi-sensor imagery. Biosyst. Eng. 2020, 193, 101-114. [CrossRef] 
123. Maimaitijiang, M.; Sagan, V.; Sidike, P.; Hartling, S.; Esposito, F.; Fritschi, F.B. Soybean yield prediction from UAV using multimodal data fusion and deep learning. Remote Sens. Environ. 2020, 237. [CrossRef]

124. Sangha, H.S.; Sharda, A.; Koch, L.; Prabhakar, P.; Wang, G. Impact of camera focal length and sUAS flying altitude on spatial crop canopy temperature evaluation. Comput. Electron. Agric. 2020, 172. [CrossRef]

125. Tucci, G.; Parisi, E.I.; Castelli, G.; Errico, A.; Corongiu, M.; Sona, G.; Viviani, E.; Bresci, E.; Preti, F. Multi-sensor UAV application for thermal analysis on a dry-stone terraced vineyard in rural Tuscany landscape. ISPRS Int. J. Geo-Inf. 2019, 8, 87. [CrossRef]

126. Parisi, E.I.; Suma, M.; Güleç Korumaz, A.; Rosina, E.; Tucci, G. Aerial platforms (uav) surveys in the vis and tir range. Applications on archaeology and agriculture. ISPRS Ann. Photogramm. Remote Sens. Spat. Inf. Sci. 2019, 42, 945-952. [CrossRef]

127. Filippo, S.; Gennaro, D.; Matese, A.; Gioli, B.; Toscano, P.; Zaldei, A.; Palliotti, A.; Genesio, L. Multisensor approach to assess vineyard thermal dynamics combining high- resolution unmanned aerial vehicle (UAV) remote sensing and wireless sensor network (WSN) proximal sensing. Sci. Hortic. 2017, 221, 83-87. [CrossRef]

128. Modica, G.; Praticò, S.; Di Fazio, S. Abandonment of traditional terraced landscape: A change detection approach (a case study in Costa Viola, Calabria, Italy). Land Degrad. Dev. 2017, 28, 2608-2622. [CrossRef]

129. Yang, G.; Liu, J.; Zhao, C.; Li, Z.; Huang, Y.; Yu, H.; Xu, B.; Yang, X.; Zhu, D.; Zhang, X.; et al. Unmanned Aerial Vehicle Remote Sensing for Field-Based Crop Phenotyping: Current Status and Perspectives. Front. Plant Sci. 2017, 8. [CrossRef] [PubMed]

130. Neely, L.; Rana, A.; Bagavathiannan, M.V.; Henrickson, J.; Putman, E.B.; Popescu, S.; Burks, T.; Cope, D.; Ibrahim, A. Unmanned Aerial Vehicles for High- Throughput Phenotyping and Agronomic. PLoS ONE 2016, 1-26. [CrossRef]

131. Sankaran, S.; Khot, L.R.; Espinoza, C.Z.; Jarolmasjed, S.; Sathuvalli, V.R.; Vandemark, G.J.; Miklas, P.N.; Carter, A.H.; Pumphrey, M.O.; Knowles, N.R.; et al. Low-altitude, high-resolution aerial imaging systems for row and field crop phenotyping: A review. Eur. J. Agron. 2015, 70, 112-123. [CrossRef]

132. Natarajan, S.; Basnayake, J.; Wei, X.; Lakshmanan, P. High-throughput phenotyping of indirect traits for early-stage selection in sugarcane breeding. Remote Sens. 2019, 11, 2952. [CrossRef]

133. Gracia-Romero, A.; Kefauver, S.C.; Fernandez-Gallego, J.A.; Vergara-Díaz, O.; Nieto-Taladriz, M.T.; Araus, J.L. UAV and ground image-based phenotyping: A proof of concept with durum wheat. Remote Sens. 2019, 11, 1244. [CrossRef]

134. Perich, G.; Hund, A.; Anderegg, J.; Roth, L.; Boer, M.P.; Walter, A.; Liebisch, F.; Aasen, H. Assessment of Multi-Image Unmanned Aerial Vehicle Based High-Throughput Field Phenotyping of Canopy Temperature. Front. Plant Sci. 2020, 11, 1-17. [CrossRef]

135. Berliner, P.; Oosterhuis, D.M.; Green, G.C. Evaluation of the infrared thermometer as a crop stress detector. Agric. For. Meteorol. 1984, 31, 219-230. [CrossRef]

136. Blum, A.; Shpiler, L.; Golan, G.; Mayer, J. Yield stability and canopy temperature of wheat genotypes under drought-stress. Field Crops Res. 1989, 22, 289-296. [CrossRef]

137. Amani, I.; Fischer, R.A.; Reynolds, M.P. Canopy temperature depression association with yield of irrigated spring wheat cultivars in a hot climate. J. Agron. Crop Sci. 1996, 176, 119-129. [CrossRef]

138. Lopes, M.S.; Reynolds, M.P. Partitioning of assimilates to deeper roots is associated with cooler canopies and increased yield under drought in wheat. Funct. Plant Biol. 2010, 37, 147-156. [CrossRef]

139. Maimaitijiang, M.; Ghulam, A.; Sidike, P.; Hartling, S.; Maimaitiyiming, M.; Peterson, K.; Shavers, E.; Fishman, J.; Peterson, J.; Kadam, S.; et al. Unmanned Aerial System (UAS)-based phenotyping of soybean using multi-sensor data fusion and extreme learning machine. ISPRS J. Photogramm. Remote Sens. 2017, 134, 43-58. [CrossRef]

140. Pavelis, G.A. Economic Survey of Farm Drainage. In Farm Drainage in the United States: History, Status, and Prospects; Georg, A., Ed.; Doc. RESUME CE 050265 Pavelis, Miscellaneous Publication Number 1455; U.S. Government Printing Office: Washington, DC, USA, 1987.

141. Fausey, N.R. Drainage management for humid regions. Int. Agric. Eng. J. 2005, 14, $209-214$.

142. Lal, R.; Taylor, G.S. Drainage and Nutrient Effects in a Field Lysimeter Study: II. Mineral Uptake by Corn. Soil Sci. Soc. Am. J. 1970, 34, 245-248. [CrossRef]

143. Freeland, R.; Allred, B.; Eash, N.; Martinez, L.; Wishart, D.B. Agricultural drainage tile surveying using an unmanned aircraft vehicle paired with Real-Time Kinematic positioning-A case study. Comput. Electron. Agric. 2019, 165, 104946. [CrossRef] 
144. Cannell, R.Q.; Gales, K.; Snaydon, R.W.; Suhail, B.A. Effects of short-term waterlogging on the growth and yield of peas (Pisum sativum). Ann. Appl. Biol. 1979, 93, 327-335. [CrossRef]

145. Du, B.; Arnold, J.G.; Saleh, A.; Jaynes, D.B. Development and application of SWAT to landscapes with tiles and potholes. Trans. Am. Soc. Agric. Eng. 2005, 48, 1121-1133. [CrossRef]

146. Allred, B.; Martinez, L.; Fessehazion, M.K.; Rouse, G.; Williamson, T.N.; Wishart, D.B.; Koganti, T.; Freeland, R.; Eash, N.; Batschelet, A.; et al. Overall results and key findings on the use of UAV visible-color, multispectral, and thermal infrared imagery to map agricultural drainage pipes. Agric. Water Manag. 2020, 232, 106036. [CrossRef]

147. Mira, M.; Valor, E.; Boluda, R.; Caselles, V.; Coll, C. Influence of soil water content on the thermal infrared emissivity of bare soils: Implication for land surface temperature determination. J. Geophys. Res. Earth Surf. 2007, 112, 1-11. [CrossRef]

148. Allred, B.; Eash, N.; Freeland, R.; Martinez, L.; Wishart, D.B. Effective and efficient agricultural drainage pipe mapping with UAS thermal infrared imagery: A case study. Agric. Water Manag. 2018, 197, 132-137. [CrossRef]

149. Williamson, T.N.; Dobrowolski, E.G.; Meyer, S.M.; Frey, J.W.; Allred, B.J. Delineation of tile-drain networks using thermal and multispectral imagery-Implications for water quantity and quality differences from paired edge-of-field sites. J. Soil Water Conserv. 2019, 74, 1-11. [CrossRef]

150. Woo, D.K.; Song, H.; Kumar, P. Mapping subsurface tile drainage systems with thermal images. Agric. Water Manag. 2019, 218, 94-101. [CrossRef]

151. Ezenne, G.I.; Jupp, L.; Mantel, S.K.; Tanner, J.L. Current and potential capabilities of UAS for crop water productivity in precision agriculture. Agric. Water Manag. 2019, 218, 158-164. [CrossRef]

152. Maes, W.H.; Steppe, K. Perspectives for Remote Sensing with Unmanned Aerial Vehicles in Precision Agriculture. Trends Plant Sci. 2019, 24, 152-164. [CrossRef] [PubMed]

153. Zhang, J.; Huang, Y.; Pu, R.; Gonzalez-Moreno, P.; Yuan, L.; Wu, K.; Huang, W. Monitoring plant diseases and pests through remote sensing technology: A review. Comput. Electron. Agric. 2019, 165. [CrossRef]

154. Khaliq, A.; Comba, L.; Biglia, A.; Ricauda Aimonino, D.; Chiaberge, M.; Gay, P. Comparison of satellite and UAV-based multispectral imagery for vineyard variability assessment. Remote Sens. 2019, 11, 436. [CrossRef]

155. McCabe, M.F.; Houborg, R.; Lucieer, A. High-resolution sensing for precision agriculture: From Earth-observing satellites to unmanned aerial vehicles. Remote Sens. Agric. Ecosyst. Hydrol. 2016, 9998, 999811. [CrossRef]

156. Houborg, R.; McCabe, M.F. High-Resolution NDVI from planet's constellation of earth observing nano-satellites: A new data source for precision agriculture. Remote Sens. 2016, 8, 768. [CrossRef]

157. Selva, D.; Krejci, D. A survey and assessment of the capabilities of Cubesats for Earth observation. Acta Astronaut. 2012, 74, 50-68. [CrossRef]

158. Tsouros, D.C.; Bibi, S.; Sarigiannidis, P.G. A review on UAV-based applications for precision agriculture. Information 2019, 10, 349. [CrossRef]

159. Borgogno Mondino, E.; Gajetti, M. Preliminary considerations about costs and potential market of remote sensing from UAV in the Italian viticulture context. Eur. J. Remote Sens. 2017, 50, 310-319. [CrossRef]

(C) 2020 by the authors. Licensee MDPI, Basel, Switzerland. This article is an open access article distributed under the terms and conditions of the Creative Commons Attribution (CC BY) license (http://creativecommons.org/licenses/by/4.0/). 